\title{
RACK1, A multifaceted scaffolding protein: Structure and function
}

\author{
David R Adams ${ }^{1}$, Dorit Ron ${ }^{2}$ and Patrick A Kiely ${ }^{3^{*}}$
}

\begin{abstract}
The Receptor for Activated C Kinase 1 (RACK1) is a member of the tryptophan-aspartate repeat (WD-repeat) family of proteins and shares significant homology to the $\beta$ subunit of G-proteins $(G \beta)$. RACK1 adopts a seven-bladed $\beta$ propeller structure which facilitates protein binding. RACK1 has a significant role to play in shuttling proteins around the cell, anchoring proteins at particular locations and in stabilising protein activity. It interacts with the ribosomal machinery, with several cell surface receptors and with proteins in the nucleus. As a result, RACK1 is a key mediator of various pathways and contributes to numerous aspects of cellular function. Here, we discuss RACK1 gene and structure and its role in specific signaling pathways, and address how posttranslational modifications facilitate subcellular location and translocation of RACK1. This review condenses several recent studies suggesting a role for RACK1 in physiological processes such as development, cell migration, central nervous system (CN) function and circadian rhythm as well as reviewing the role of RACK1 in disease.
\end{abstract}

Keywords: RACK1, WD-repeat, guanine nucleotide binding protein 2-like 1, $(G \beta)$, heterotrimeric G-proteins, PKCßII, scaffolding protein

\section{Introduction}

\section{The WD-repeat family of proteins}

The tryptophan, aspartic acid repeat (WD-repeat containing proteins are an ancient conservative family of proteins found in prokaryotes and all eukaryotes [1]. They are involved in almost every signaling pathway and are associated with many genetic diseases. To date over 100 WD-repeat proteins have been assigned with an approved name and designation in the human nomenclature database. Genes encoding WD-repeat proteins are found on all chromosomes except 20, 22 (a pseudogene FBXW4P1 has been reported in chromosome 22), and the Y chromosome http://www.genenames.org This reflects their diversity and importance as a family, and suggests that their expression is regulated by a variety of signaling pathways. WD-repeats themselves are sequences of typically 44-60 amino acids in length ending at the C-terminus with a signature WD dipeptide or its equivalent (Figure 1). The motifs were first identified as repeating segments of homologous sequence within

\footnotetext{
* Correspondence: Patrick.Kiely@ul.ie

${ }^{3}$ Department of Life Sciences, and Materials and Surface Science Institute

University of Limerick, Limerick, Ireland

Full list of author information is available at the end of the article
}

the primary structure of the transducin G $\beta$ subunit and CDC4 [2]. Detailed analysis with a larger cohort of proteins revealed that the repeats are also typified by a characteristic GH dipeptide usually residing some 11-24 residues from the $\mathrm{N}$-terminus, though neither the $\mathrm{GH}$ nor WD signature is absolutely conserved [3-5]. Several other characteristic amino acids contribute to the repeat, most notably an aspartic acid located 6 residues before the WD dipetide, but it is the collective critical mass of such features rather than the absolute conservation of any individual amino acid that establishes the identity of a sequence as a WD-repeat [6]. Given the variable number of residues at the $\mathrm{N}$-terminal end of these units, sequence databases tend to map the repeats of WD-proteins between GH and WD dipeptides for convenience (Figure 1). The basic criterion for inclusion of a protein into the family is the presence of at least four of these repeat sequences to generate a WD-domain. These domains adopt a $\beta$-propeller structure, where the propeller fold is characterised by blades that are arranged radially around a central axis [3,7-10] (Figure 2). The conserved propeller structure is maintained by welldefined hydrogen bonding networks and intra-chain hydrophobic interactions (vide infra), although different 


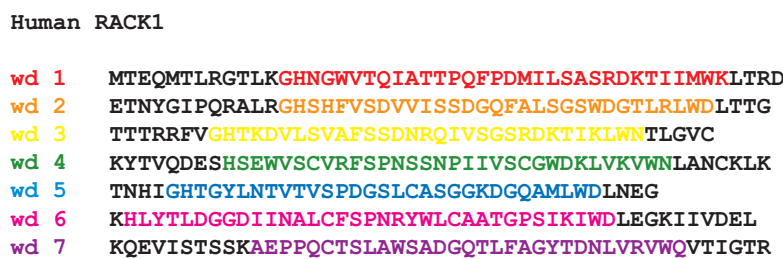

Figure 1 Sequence of RACK1 depicting WD-repeats. RACK1 is a 317 amino acid protein with seven 40 amino acid repeats which are defined by sequences flanked by GH and WD dipeptides.

WD-repeat proteins appear to adopt distinct folding orders for their constituent propeller blades [9,11]. In principle, a single $\beta$-propeller subunit may comprise four to eight blades $[4,8]$, although at present only 7 bladed or 8-bladed WD-repeat propellers have been characterised by X-ray diffraction studies-the majority being 7-bladed structures consistent with the proposal that this is the optimal $\beta$-propeller fold [12]. Proteins are known with more than eight WD-repeats, but these assume tertiary structures with multiple propeller subunits (reviewed in [6]).

Although there is no single function for WD-repeat proteins, they share a common role in scaffolding protein complexes, often with multiple and competing partners, thereby serving as hubs for spatiotemporal orchestration of signaling events across diverse pathways. WD-repeat proteins themselves lack any enzymatic activity, but they are subject to post-translational modification, suggesting ways by which their cellular location and protein partnerships may be modulated. The lack of a direct catalytic enzymatic function for the protein family contrasts with other $\beta$-propeller-forming proteins, many of which exhibit enzymatic activity [8].

The most exstensively studied WD-repeat protein to date is the G-protein $\beta$ subunit (G $\beta)[7,13]$, which exists in a complex with the $\gamma$ subunit $(\mathrm{G} \gamma)$. G $\beta \gamma$ reversibly

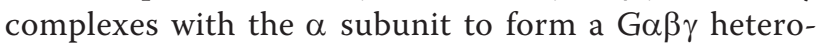
mer that associates with G-protein-coupled receptors (GPCRs) to enable transduction of extracellular signals. Upon ligand binding to a GPCR, the $\alpha$ subunit dissociates from the $G \beta \gamma$ heterodimer, resulting in the activation of various signaling cascades (reviewed in $[14,15]$ ). The mode of interaction of G $\beta$ with binding partners has become increasingly clear with the emergence of crystal structures for $\mathrm{G} \beta$ in various complexes with $\mathrm{G} \alpha$ / G $\gamma,[9,10,16,17]$, phosducin [18-20], GPCR Receptor Kinase 2 (GRK2) [21-23], Regulator of G-protein Signaling 9 (RGS9) [24,25], and the Parathyroid Hormone 1 Receptor (PTH1R) [26]. Interestingly, WD-domains do not operate simply as standalone platforms for scaffolding protein complexes. Thus, several WD-proteins including RACK1 form both homodimers and heterodimers [27-29]. Moreover, some WD-repeat proteins contain other domains in addition to the WDrepeat sequences that increase the number of binding partners, scaffolding properties and overall function of the protein. For example, the $\beta$-transducing repeat-containing protein $1(\beta-\mathrm{TrCP} 1)$ is a ubiquitin ligase with both WD-repeat and F-box domains as well as a RING domain. $\beta$-TrCP1 is required for the degradation of regulatory proteins such as Snail and p53 [30,31], and the WD-repeats increase its binding cohort and regulate its sub-cellular location, allowing the protein to also have a role in transcription and in regulating circadian rhythm [32-34]. WD-repeat and (suppressor of cytokines signaling) SOCS box-containing protein 1 (WSB1) is a ubiquitin ligase subunit, induced by Hedgehog signaling, that contains in addition to its WD-domain a SOCS-box that mediates its interaction with a ubiquitinating catalytic core complex $[35,36]$. WSB1 promotes cell survival in neuroblastoma [37]. Novel Nuclear Receptor Interaction Protein (NRIP) is a nuclear receptor with two WDrepeat domains which also has a nuclear localization signal [38]. NRIP interacts with the androgen receptor [39] and has recently been implicated in viral replication [40].

As our knowledge of the WD-repeat family of proteins expands, we are seeing that the members are involved in most signaling pathways (reviewed in [1]). It is no surprise, therefore, that WD-repeat proteins play a critical role in various human diseases. Subtle changes in the expression levels of WD-proteins can have a dramatic effect on protein complex assembly and on key signaling pathways. In this review, we focus on RACK1, a $36-\mathrm{kDa}$ protein with seven WD-repeats that is homologous to $G \beta$, and that is one of the best known and studied members of the WD-repeat protein family. We focus on its structure, binding partners, subcellular localization, its role in signaling pathways and its function in normal physiological responses as well as in pathological conditions.

\section{RACK 1 is a scaffolding protein}

RACK1 is a highly conserved intracellular adaptor protein with significant homology to G $\beta$. RACK1 was originally cloned from a chicken liver cDNA library and human B-lymphoblastoid cell line (B-LCL) [41]. Several years later, Mochly-Rosen's group cloned the protein from a rat brain c-DNA library which was screened for gene products that bind purified rat brain PKC in the presence of its activators (phosphatidylserine, diacyglycerol and calcium) [42]. Given the association of RACK1 with the active conformation of PKC $\beta I I$, the protein was named Receptor for Activated C Kinase 1 (RACK1) [42-45] (Figure 3). However, it is now well established that RACK1 interacts with a large number of 


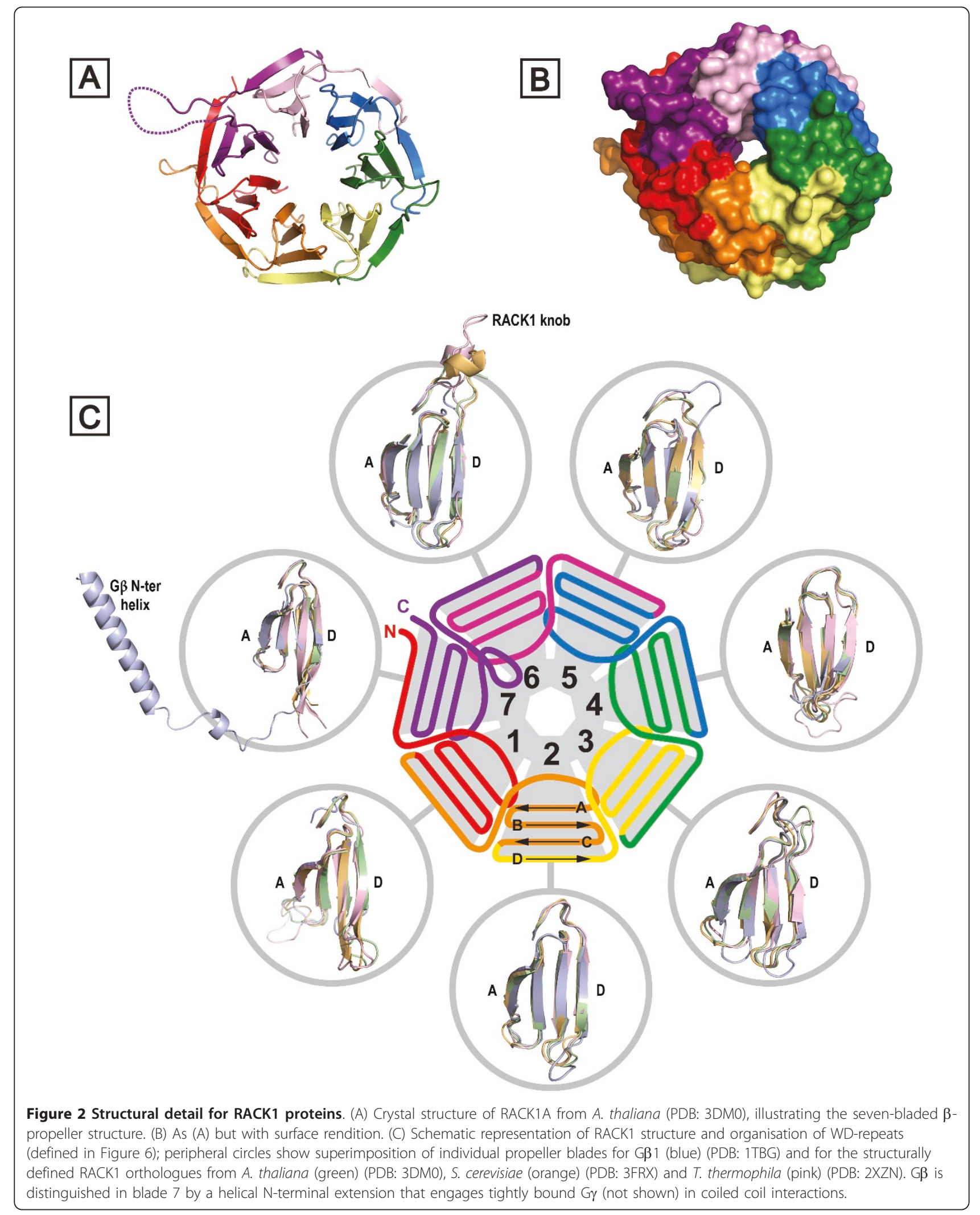




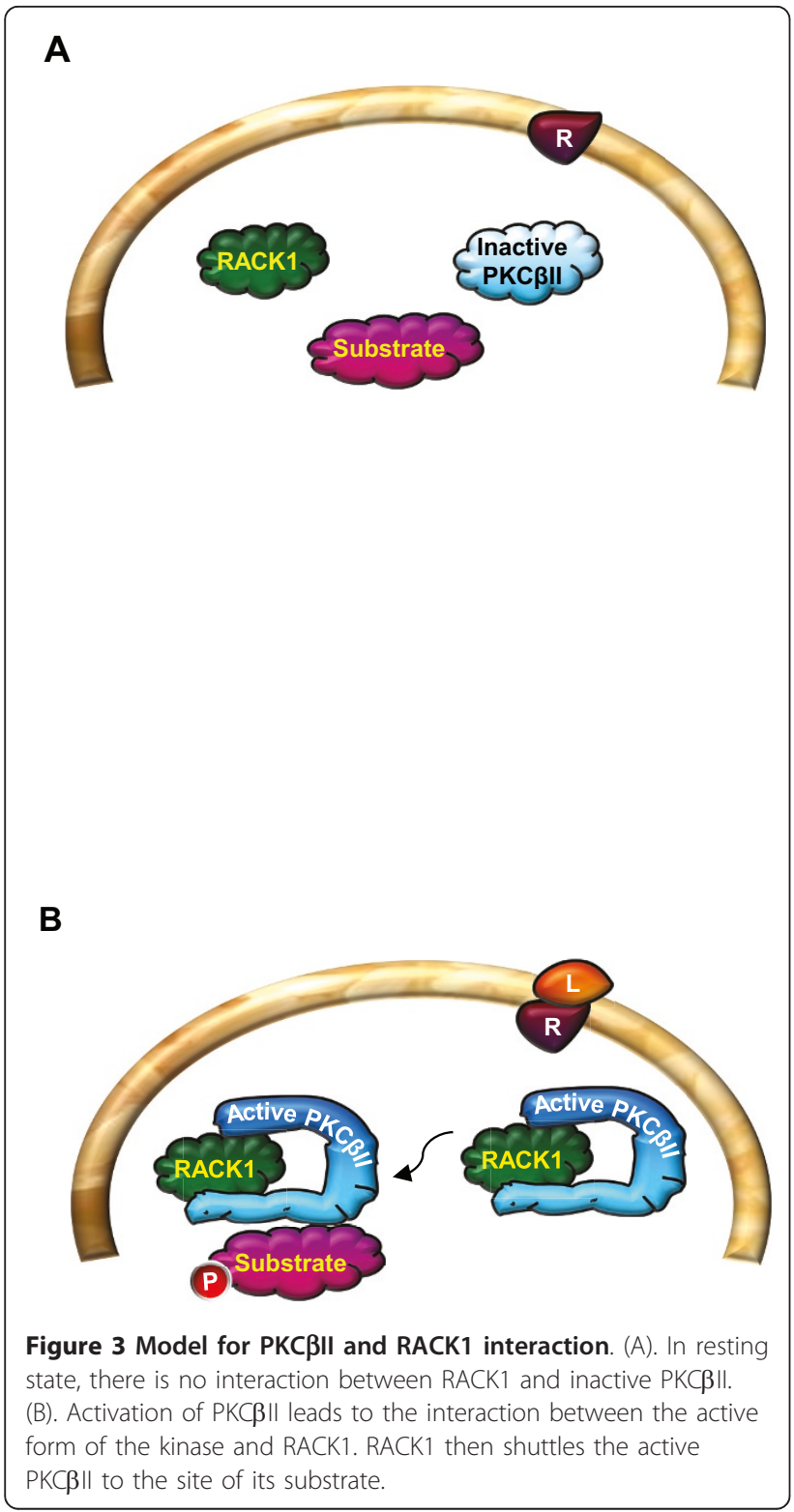

proteins either directly or as part of a larger complex. As a scaffold protein, RACK1 integrates inputs from distinct signaling pathways and is critical for fundamental cellular activities such as cell proliferation, transcription and protein synthesis, as well as various neuronal functions. RACK1's scaffolding properties are mediated by the presence of seven WD-repeats [46,47] (see also sections 2.2 and 2.3) that present multiple protein-binding sites and facilitate interaction with specialized protein docking modules, including $\mathrm{SH} 2$ domains ( $\mathrm{Src}$ and $\mathrm{Fyn}$ ) $[48,49]$, plextrin homology $(\mathrm{PH})$ domains (dynamin and p120GAP) [50,51] and C2 domains (PKCs) $[43,45]$. In addition, RACK1 was pulled out in a yeast two-hybrid screen as a binding partner of the first PDZ domain of the human $\mathrm{Na}^{+} / \mathrm{H}^{+}$exchanger regulatory factor
(NHERF1) [52]. RACK1 also forms a heterodimer with at least one other WD-repeat protein, G $\beta[27,28,53]$. The formation of the RACK1-G $\beta$ heterodimer has been shown to enable efficient cross-talk between signal transduction pathways mediated by GPCRs and by ligand-gated ion channels, specifically between the cAMP/PKA pathway and the N-methyl D-aspartate receptor (NMDAR) [29] (Figures 4 and 5). RACK1 also functions as a homodimer enabling the expansion of its binding partners $[28,29,49,53,54]$. For example, the formation of a homodimer enables the simultaneous interaction of RACK1 with Fyn and with the NR2B subunit of the NMDAR, even though Fyn and NR2B share the same binding site on RACK1 [29,49,55-57] (Figure 5A).

The proteins interacting with RACK1 fall into two broad categories, those constitutively bound and those that are stimulus-dependent or transient. RACK1

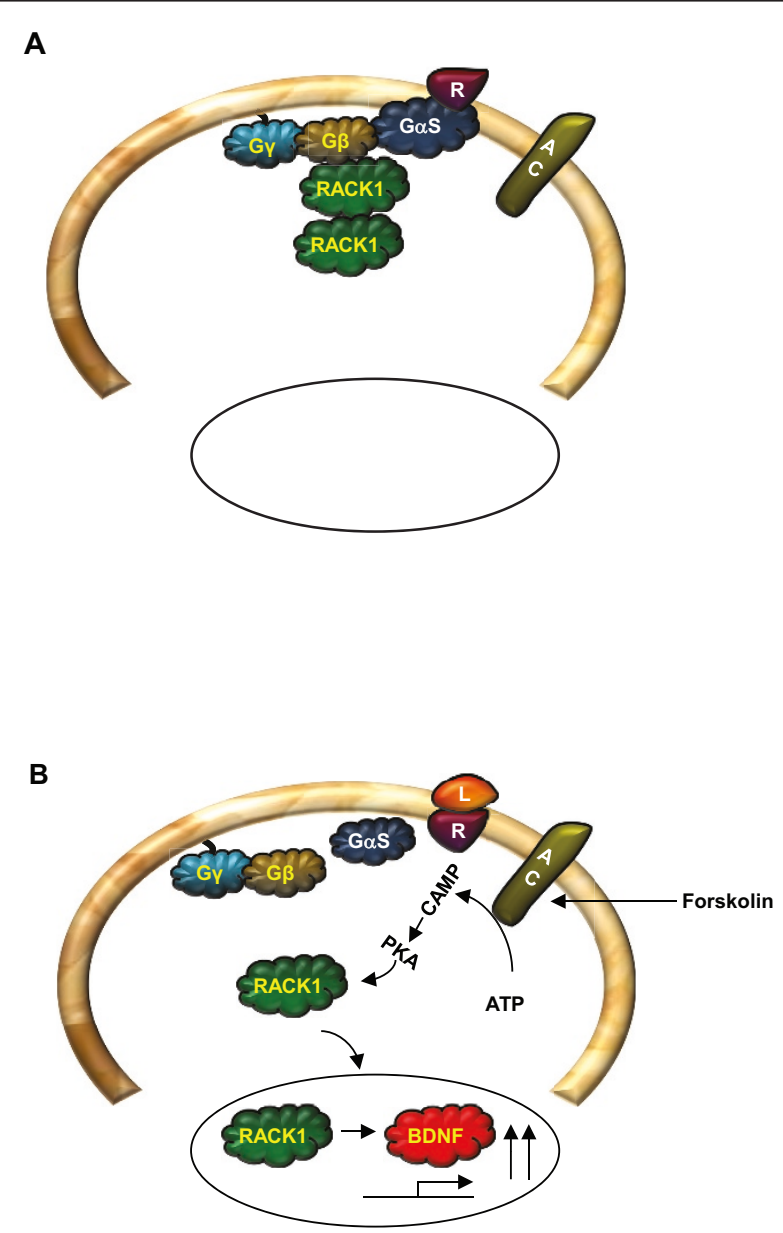

Figure 4 Model for CAMP/PKA-mediated nuclear translocation of RACK1. (A). In resting state, RACK1 forms homodimers as well as heterodimers with $G \beta$. (B). Activation of the CAMP/PKA pathway leads to the dissociation of RACK1 from the complex and its translocation to the nucleus. In the nucleus RACK1 contributes to CAMP/PKA mediated increase in BDNF transcription. 


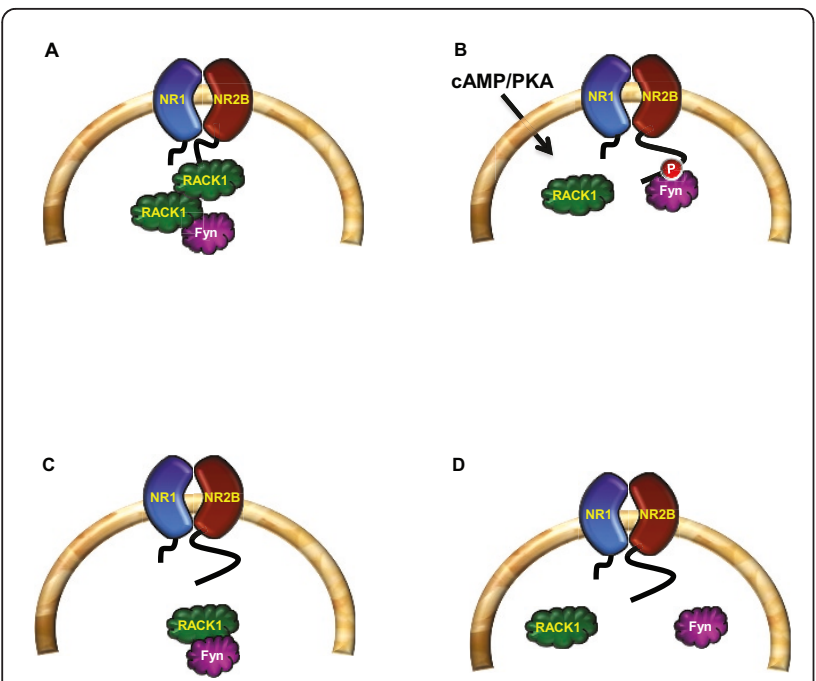

Figure 5 Differential compartmentalization of RACK 1 in the brain. (A). In hippocampal and dorsal striatal neurons, RACK1 is associated with both the NR2B subunit of the NMDAR and Fyn kinase. (B). CAMP/PKA activation or alcohol exposure leads to the release of RACK1 from the complex, enabling Fyn to phoshorylate the tyrosine residues on the cytoplasmic tail of the NR2B. (C). In the cerebral cortex, RACK1 is bound to Fyn but not to the NMDAR. (D) In the ventral striatum, RACK1 is not associated with either protein.

binding partners have been identified at various locations throughout the cell, and one important functional role for RACK1 is undoubtedly to shuttle some of these binding partners to particular intracellular sites. However, in addition to this role, a key aspect of the function of RACK1 is its capacity to modulate the enzymatic activity of its binding partners, either promoting or suppressing the activity of bound enzymes. For example, RACK1 stabilizes the activity of protein phosphatase $2 \mathrm{~A}$ (PP2A) $[58,59]$ and maintains the active conformation of PKC $\beta$ II $[42,45,60]$ (Figure 3). In contrast, RACK1 binds to the tyrosine kinases Src and Fyn to maintain these kinases in an inactive state until the appropriate signal occurs to trigger dissociation of the complex [29,49,55-57,61,62] (see also Figure 5A). Thus, RACK1 plays a key role in stabilizing the active or inactive conformation of its partners.

\section{RACK1, Gene and Structure}

\section{RACK1: Gene, promoter and expression}

Human RACK1 is encoded by the gene, GNB2L1 [guanine nucleotide binding protein (G-protein), beta polypeptide 2-like 1], which has 8 exons and 7 introns $[63,64]$. The open reading frame of the gene is $1142 \mathrm{bp}$ and it encodes for a protein with 317 amino acids, registering as a $36 \mathrm{kDa}$ protein on an SDS PAGE gel. Studies probing the evolution of human RACK1 suggest that human, rat and mouse RACK1 form a different subgroup and are therefore strictly paralogs of RACK1 in other organisms, but these studies nevertheless indicate that RACK1 is strongly conserved through evolution [64]. Indeed, sequence alignments of RACK1 species from diverse organisms - Tetrahymena thermophila, Saccharomyces cerevisiae, Arabidopsis thaliana and Drosophila melanogaster - reveals a $43-76 \%$ sequence identity (Figure 6). GNB2L1 is mapped to chromosome $5 \mathrm{q} 35.3$, in close proximity to the telomere of chromosome 5 [63]. At least 6 other genes have been mapped to this region and it is a reported location for cytogenetic and molecular abnormalities [65-68]. The promoter region of GNB2L1, which was found to have two alternative start sites of transcription, has binding sites for cardiac/smooth muscle specific c-Rel (NF- $\kappa \mathrm{B})$ [63,69]. RACK1 is highly expressed in most tissues [70], including the brain [71]. The expression of RACK1 appears to be tightly regulated and changes in RACK1

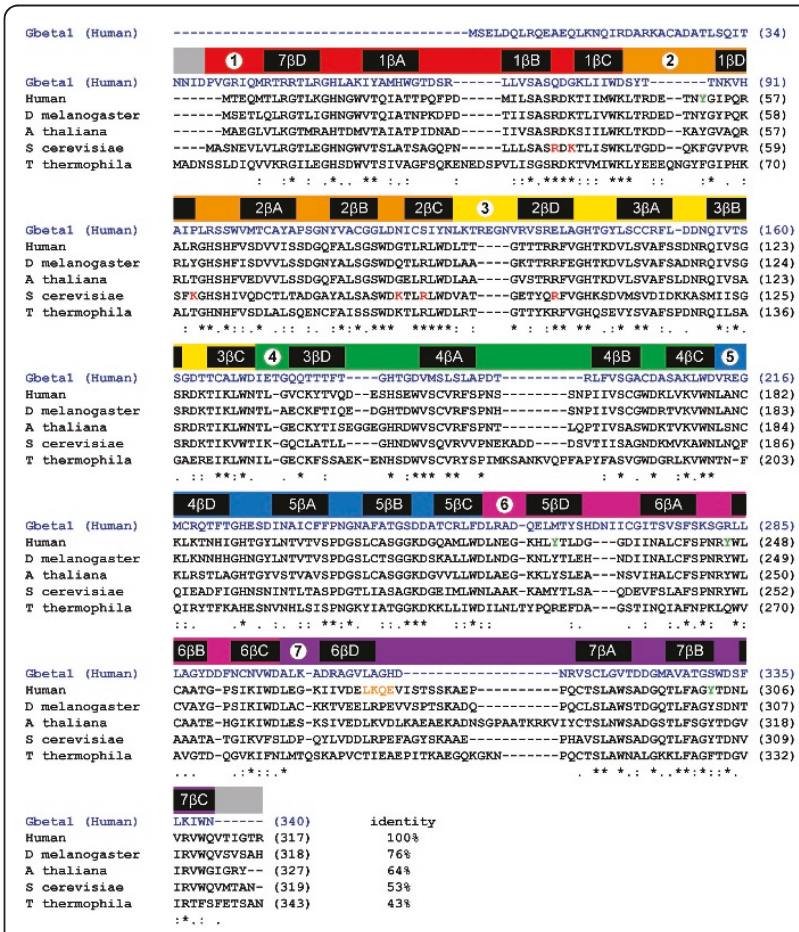

Figure 6 Sequence alignment of G $\beta 1$ (UniProtKB accession ID: P62873) vs RACK1 orthologues from Homo sapiens (P63244), Drosophila melanogaster (018640), Arabidopsis thaliana (024456), Saccharomyces cerevisiae (P38011) and Tetrahymena thermophila (E6PBV0). This alignment is similar to that presented by Ullah et al [81] but revised to include the sequence of the T. thermophila protein. WD-repeats and secondary structural elements are defined above the sequences. The percentage sequence identity between human RACK1 and the orthologues from other species is defined at the end of the alignment. The homology index for the proteins (excluding $\mathrm{G} \beta 1$ ) is presented below the sequence, where fully conserved residues are marked with an asterisk; conservative and semiconservative positions are marked with colons and periods respectively. Residues marked in red in the yeast sequence engage rRNA in the eukaryotic 40S ribosomal subunit (see text). 
expression are associated with cancer (see section 6.1.). It has also been suggested that changes in RACK1 expression contribute to brain pathologies [72-74] (see section 6.2.). This is supported by observations from our group and others that RACK1 is inhibitory to the growth of normal fibroblasts and can only be overexpressed in transformed cells or cells that over-express the IGF-1R [75-77]. Interestingly, a binding site for the glucocorticoid receptor is present in the GNB2L1 promoter [63], suggesting a mechanism by which RACK1 expression levels may change with aging. This is significant given that RACK1 affects the subcellular distribution and function of numerous proteins and, as a result, plays an essential role in regulating signaling pathways in many key biological processes $[46,47]$. Indeed, over 80 binding partners of RACK1 have been reported to date, (although several of these remain uncharacterised and may not bind to RACK1 directly), and as new partner proteins emerge, the important contribution that RACK1 makes to signaling pathways is becoming clearer. It is probable that RACK1 engages in different sets of signaling pathways in different cells, reflecting the cell type and the differential expression of its binding partners. In this way, RACK1 plays distinct roles in different cell types, even when the expression of RACK1 itself remains relatively constant.

\section{Structure of RACK1}

G $\beta$ was the first WD-repeat protein to be characterised by $\mathrm{X}$-ray crystallography $[9,10,16]$. Numerous crystal structures have since emerged for WD-repeat proteins $[9,10,78]$ and these now include recently determined structures for three RACK1 species: RACK1A from A. thaliana, Asc1p from $S$. cerevisiae and RACK1 from T. thermophila at 2.4, 2.1 and $3.9 \AA$ resolution, respectively [79-82]. The $T$. thermophila protein structure was obtained as a complex with the $40 \mathrm{~S}$ small ribosomal subunit from this protozoan. A structure for the yeast RACK1 orthologue was also determined in complex with the $40 \mathrm{~S}$ ribosomal subunit at similar resolution (4.15 ̊) [83]. These structural studies confirmed that RACK1 adopts a seven-bladed $\beta$-propeller structure consistent with the predictions of earlier homology modelling studies based on G $\beta$ and other WD-repeat proteins [46,78-81]. The $A$. thaliana protein was the first of the three RACK1 orthologues to be structurally defined and, of the three, it exhibits the highest sequence homology to human RACK1, with 64\% residue identity [81] (Figure 6). In contrast to metazoans, where RACK1 is expressed from a single gene, $A$. thaliana possesses three genes-RACK1A, RACK1B and RACK1C - for closely related proteins, with the sequences for RACK1B and RACK1C (not shown) exhibiting similar levels of homology to the human protein. The structure of RACK1A is shown in Figure 2A. Each propeller blade consists of a four-stranded antiparallel $\beta$-sheet, where strand A lines the central canal of the protein, a channel of $\sim 9 \AA$ width (Figure 2B), and strand D is presented on the outer circumference. Adjacent blades are connected by a loop bridging from strand $\mathrm{D}$ on one blade to strand $\mathrm{A}$ on the next. These loops are exposed on the top face of the propeller blade, as are the $\beta$-turns linking strands $B$ and $C$ in each blade. The loops connecting strand $\mathrm{A}$ to $\mathrm{B}$ and strand $\mathrm{C}$ to $\mathrm{D}$ in each blade are located on the reverse, slightly larger face of the propeller.

The WD-repeats of RACK1, as with all proteins that adopt this fold, overlap two adjacent propeller blades to provide an interlocking architecture. Each repeat encompasses the D-strand of one blade and strands A, B and C of the next, terminating in the signature WD dipeptide at the end of strand $C$ such that the aspartic acid (or equivalent residue) is exposed on the propeller's lower face. The tryptophan, which is sometimes replaced by phenylalanine or tyrosine, is sandwiched between adjacent blades and plays an important role in inter-blade spacing (Figures 2 and 6). As the N-terminal sequence in the first WD-repeat contributes strand D of the seventh blade, hydrogen bonding to the strand $C$ sequence of the last repeat, the assembly is sealed with a 'Velcro-like' fastening to complete the toroidal structure [5]. Superimposition of the available RACK1 crystal structures with human $G \beta_{1}$, shown for individual propeller blades in Figure $2 C$, reveals that the greatest structural variation lies in the A-B, C-D and D-A loops, which are of variable length. Most notably, the D-A loop between blades 6 and 7 in the RACK1 species is 8-19 residues longer than the cognate region of $G \beta_{1}$ and forms a pronounced knob-like projection from the upper face of the propeller (disordered in the crystal structure of $A$. thaliana RACK1A). In contrast to the three other loops, the central B-C hairpin of each blade adopts a tight $\beta$-turn with a strongly conserved backbone conformation. Some $85 \%$ of known WD-repeats possess an aspartic acid at the middle position of the three residues usually present in the B-C turn [11], and this highly conserved residue forms a salt bridge with the histidine of the glycine-histidine $(\mathrm{GH})$ signature dipeptide (when present) as shown in Figure 7. This GH interaction plays an important role in defining the trajectory of the inter-blade D-A loop which hosts the $\mathrm{GH}$ dipeptide and therefore in stabilising the propeller structure. A network of additional hydrogen bonded interactions between strongly conserved residues at specific locations within the WD-repeat also maintains the integrity of blade structure. Thus, the histidine of the $\mathrm{GH}$ dipeptide is characteristically hydrogen bonded to a serine (or threonine) on $\beta$-strand $\mathrm{B}$ located in the $\mathrm{P}-4$ position relative to the conserved aspartic acid (P-0) of the $\mathrm{B}-\mathrm{C}$ turn. This serine is usually hydrogen bonded in turn to the indolic $\mathrm{NH}$ of the WD signature tryptophan (occupying the $\mathrm{P}+6$ position). The structure of the $\mathrm{B}-\mathrm{C}$ turn is 


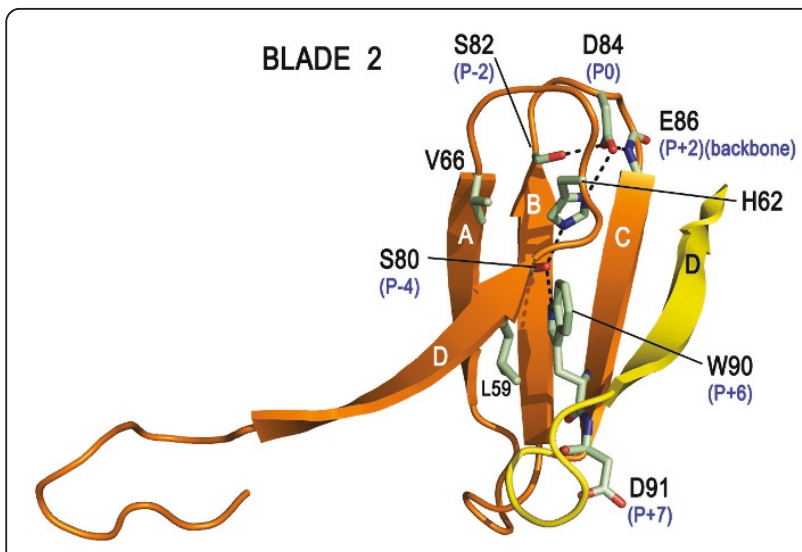

Figure 7 Summary of conserved interactions in 'typical' WDrepeats responsible for maintaining the structural integrity of propeller blades 1-5 in RACK1. Interactions are illustrated for blade 2 of the $A$. thaliana RACK1A structure (PDB: 3DM0). The second WD-repeat (as defined in Figure 6) is shown in its entirety (orange ribbon) and contributes $\beta$-strand $D$ to blade 1 plus strands $A, B$ and $C$ of blade 2 , terminating in the WD signature residues (W90-D91). Strand D of blade 2 is provided by residues in the third WD repeat (yellow ribbon). A highly conserved Asp residue (D84) occupies the central position of the B-C turn and is networked by hydrogen bonds to residues in the P-2 and P+2 positions ( 882 side chain, E86 backbone) as well as through a salt bridge to the signature GH His (H62) in the D-A loop between blades 1 and 2 . H62 is further networked with a hydrogen bond to $\mathrm{S} 80$ on $\beta$-strand B and a hydrogen bond between 580 and W90 ( $\beta$-strand C). Important non-polar interactions regulate blade packing such as contact between W90 and residues on the reverse face of blade 1 (L59) and between V66 ( $B$-strand $A$ ) and the reverse face of the B-C hairpin of blade 1 (not shown). B-C hairpin positions relative to the consensus Asp (P0) are marked in blue.

additionally defined by an engagement between the P-0 aspartate side chain and the peptide backbone $\mathrm{NH}$ at the $\mathrm{P}+2$ position (i.e. the first amino acid in $\beta$-strand $\mathrm{C}$ ). The final residue in $\beta$-strand $B$ (at the $\mathrm{P}-2$ position) is invariably small (Ser, Gly or Ala) for typical blades ${ }^{1}$ in order to accommodate the folding of the aspartic acid side chain. In the majority of instances the P-2 residue is serine, and in these cases the residue also engages the aspartate with a hydrogen bond to strengthen the local structure of the protein in that region. Non-polar interactions also play an important role in establishing the $\beta$-propeller structure however. For example, the opening residue in $\beta$-strand $A$ that lies proximal to the $\mathrm{B}-\mathrm{C}$ turn is almost invariably valine or isoleucine and fits into the space between the $\mathrm{B}$ and $\mathrm{C}$-strands of the preceding propeller blade, directly behind the P-0 aspartic acid of the B-C turn on that blade and regulating inter-blade spacing at that point. The WD signature tryptophan (or phenylalanine/tyrosine replacement) projects from the face of each propeller blade to pack against a bulky residue (frequently leucine) located at the end of the D-strand and projecting from the rear of the preceding blade.
The features described above and summarised in Figure 7 are tightly conserved across blades 1-5 of the RACK1 proteins and are responsible for a highly regular and 'typical' organisation to the core of the propeller blades for this major segment of the proteins. Some notable deviations are seen in the core organisational elements for blades 6 and 7, however, and these are likely associated with the RACK1 sequence insert in the D-A loop between these two blades. This loop lacks the characteristic GH signature dipeptide to engage the conserved Asp of the B-C turn in blade 7. Instead, an Arg on $\beta$-strand $\mathrm{C}$ of blade 7 provides a surrogate salt bridge in lieu of the signature $\mathrm{GH}$ to stabilise the blade $7 \mathrm{~B}-\mathrm{C}$ hairpin. This is illustrated in Figure 8 with the yeast RACK1 orthologue, where the D-A loop between blades 6 and 7 is of similar length to human RACK1 and fully ordered in the crystal structure. The cognate loop of

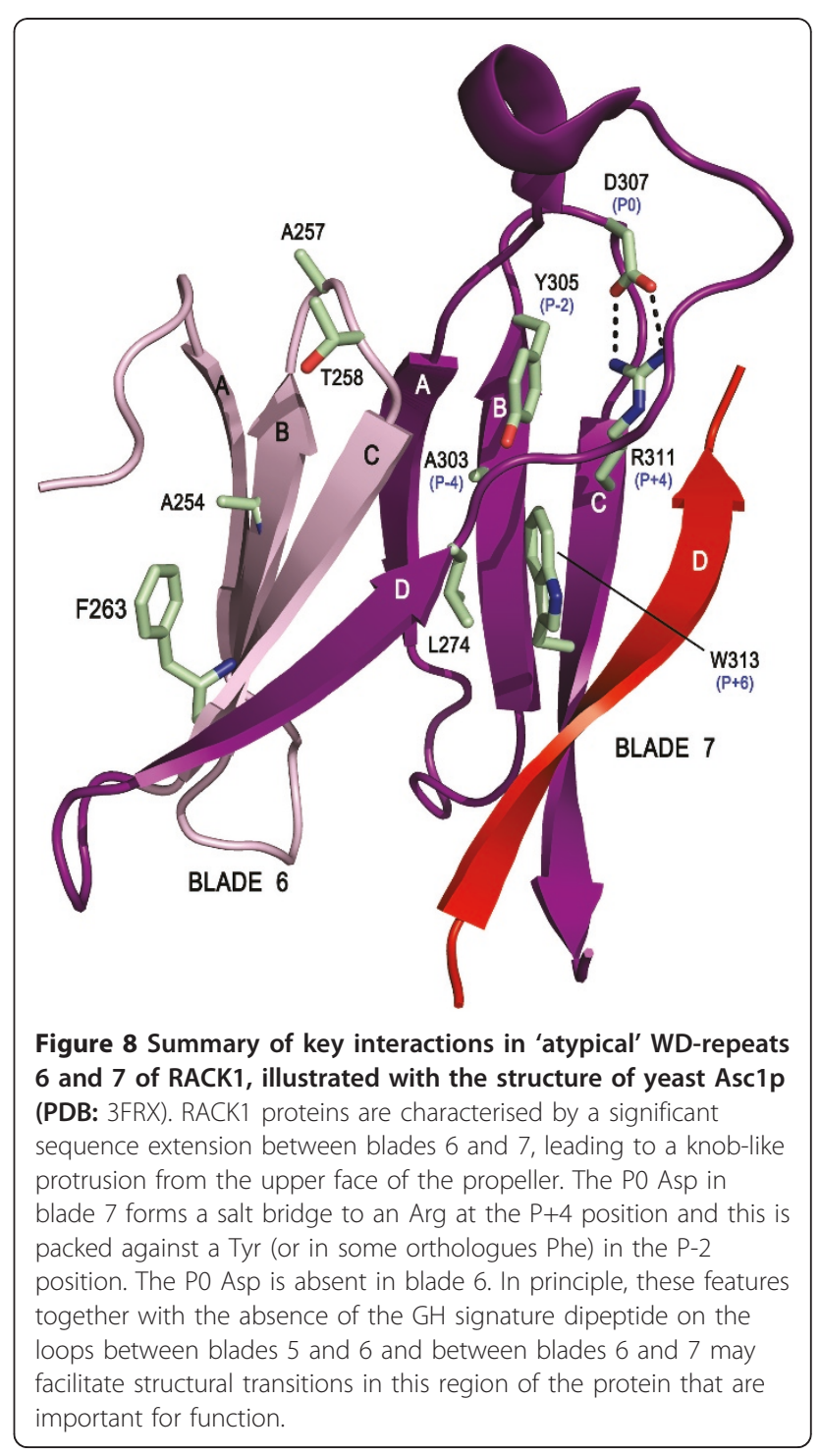


RACK1 proteins in plants, as with $A$. thaliana, is significantly extended by comparison. The arginine residue (R311) that contributes the salt bridge to the B-C hairpin of blade 7 lies in the $\mathrm{P}+4$ position relative to the aspartic acid (D307) and is packed against a tyrosine side chain (Y305) in the P-2 position of this atypical WD-repeat. In contrast, as noted above, the P-2 position is taken by Ser or Gly in typical WD-repeats (Figure 7). In blade 7 this rare occurrence of a Tyr is associated with the establishment of pi-cation interactions with the P+4 Arg (Figure 8). Significantly, the tyrosine is conserved across RACK1 orthologues of higher organisms and is a known phosphorylation site (vide infra) [58], suggesting a functionally important role for the atypical structure of this RACK1 WD-repeat. Indeed, the scaffolding of several proteins is known to be mediated by blades 5-7 of RACK1.

The D-A and B-C loops of WD-repeat proteins alternate with one another in sequence to generate the upper face of their $\beta$-propeller structures (as presented in Figure 2). Thus, the extended D-A loop that forms the RACK1 knob between blades 6 and 7 is followed by the $\mathrm{B}-\mathrm{C}$ hairpin on blade 7 and preceded by the corresponding hairpin on blade 6. Given the atypical features just described in the B-C hairpin of blade 7 , it is unsurprising that the corresponding hairpin of blade 6 , immediately preceding the knob, should also differ from the typical consensus features summarised in Figure 7. The key distinction in this hairpin is the deletion of the central aspartic acid residue of the $\beta$-turn, and a very tight turn of two residues serves to reverse the backbone between $\beta$-strands $B$ and $C$ in blade 6 , though neither of the residues at this site is conserved across RACK1 orthologues (Figure 6). In the yeast structure, the turn comprises A257 and T258 (Figure 8). Deletion of the aspartic acid from the B-C turn also appears to be associated with loss of the signature $\mathrm{GH}$ dipeptide from the preceding D-A loop between blades 5 and 6 , where, in a typical WD-repeat, the histidine would engage the aspartic acid of the B-C turn. Thus, RACK1 proteins lack the $\mathrm{GH}$ motif in the D-A loops between both blades $5 / 6$ and blades 6/7. Significantly, the absence of the $\mathrm{GH}$ in these loops appears to make the presence of the consensus $\mathrm{P}-4$ serine on $\beta$-strand $\mathrm{B}$ redundant in blades 6 and 7, and the serine is replaced by alanine in both blades of yeast and mammalian RACK1 proteins. As shown in Figure 7, the P-4 serine hydrogen bonds to the preceding $\mathrm{GH}$ signature histidine in typical WDrepeats. Substitution of the $\mathrm{P}-4$ serine by alanine has a further effect, however, and abolishes the additional hydrogen bond to the WD signature tryptophan that is seen in typical WD-repeats. The abolition of this hydrogen bond appears to be associated with a change in the conformation of the tryptophan side chain in blade 7 of the yeast protein, where the indolic $\mathrm{NH}$ is no longer constrained in a hydrogen bond towards strand $\mathrm{B}$ but re-orientated towards strand D instead. Interestingly, in blade 6 of the yeast structure, the WD tryptophan is replaced by phenylalanine, and it is conceivable that where the P-4 serine of the B-strand is substituted by a non-hydrogen bonding residue evolutionary conservation of the signature tryptophan is also relaxed.

\section{Structural basis for RACK1-scaffolded protein associations}

The available crystal structures for G $\beta$ and other WDrepeat proteins have established the structural basis for scaffolded interactions with a range of partner proteinsG $\alpha / G \gamma$, phosducin, GRK2, RGS9 and PTH1R in the case of $\mathrm{G} \beta$ for example (vide supra)-and the current understanding of WD-repeat protein docking modes has recently been reviewed in detail [6]. Unfortunately, structural information relating specifically to the interactions of RACK1 with its numerous protein partners currently remains very limited.

Scanning peptide arrays, mutagenesis studies and competition experiments with RACK1-derived peptides have identified probable loci on the surface of RACK1 that may contribute to protein-protein interfaces for some of RACK1's partners. The most detailed information relating to RACK1-biomolecule associations currently available, however, has emerged from structural studies with ribosomes. Initial breakthroughs came with the use of cryoelectron microscopy (cryo-EM) techniques, affording a low resolution (11.7 $\AA$ ) structure for the yeast $40 \mathrm{~S}$ ribosomal subunit that identified the position of bound RACK1 on the head region proximal to the mRNA exit channel [84]. The cryo-EM map of a mammalian $40 \mathrm{~S}$ subunit followed at slightly higher resolution $(8.7 \AA$ ) $[85]$. These studies pre-dated the RACK1 $\mathrm{X}$-ray crystal structures, and the ribosome structure was constructed by fitting homology models of individual ribosomal components (templated on G $\beta$ in the case of RACK1) to the cryo-EM map. Both models implicated helices 39 and 40 of the $18 \mathrm{~S}$ ribosomal RNA as the primary anchoring region for RACK1, with contact mediated largely by blades 1 and 2 and their associated loops. Consistent with this, binding of RACK1 to ribosomes is compromised by mutation of a number of basic residues that are conserved across the identified RNA binding interface of RACK1 species but that are absent at the cognate sites in G $\beta$ (Figure 6). Thus, a double charge reversal mutation (R38D:K40E) in the RDK B-C turn of blade 1 almost fully ablates binding of the yeast protein (Asc1p) to the ribosome [79,84]. Alanine mutations for K87, R90 and R102, residues that project from the B-C turn and edge of blade 2 in Asc1p, also attenuate binding to the ribosome [79]. Similarly, alanine mutagenesis of $\mathrm{K} 62$, located on the edge of 
blade 1, weakens binding to the ribosome [79]. At least four of these residues (K40, K87, R90, R102) are expected to make direct contact with the sugar-phosphate backbone of the ribosomal RNA, forming salt bridge interactions with the phosphates. Interestingly, neither K62 nor K87 are fully conserved across RACK1 homologues, however, indicating some species differences in the interaction of RACK1 with the RNA of the $40 \mathrm{~S}$ ribosomal subunit. Nevertheless, all the available data from structural studies with eukaryotic ribosomes points to a similar mode of engagement involving the edge of blades 1 and 2 and accompanying loops on the top face of the $\beta$-propeller. Interestingly, RACK1 associates with polysome bound polyA-mRNA enabling PKC $\beta I$ II to phosphorylate polyA-mRNA-associated proteins and control localized protein synthesis in neurons [86].

RACK1 binding to the eukaryotic ribosome is not purely mediated by interactions with the 18S RNA however. Additional contact occurs between RACK1 and coassociated ribosomal proteins and, following the studies described above, cryo-EM maps have emerged for ribosomes providing more detail for the assembled proteins [87-89]. Very recently X-ray crystal structures have also been obtained for complete eukaryotic ribosomal subunits $[80,83]$. These studies have defined the interfaces on RACK1 for co-association with three eukaryotic ribosomal proteins - rpS3e, rpS16e and $\operatorname{rpS17e~-~as~illu-~}$ strated with the $40 \mathrm{~S}$ subunit from T. thermophila at 3.9 $\AA$ resolution (Figure 9). The most extensive protein contacts occur with a three-helix bundle formed by the $\mathrm{N}$ terminal region of $\mathrm{rpS17e}$, which occupies one face of the RACK1 propeller. The model suggests that a number of salt bridges are formed at the interface between the two proteins, and these contacts involve the RDK turn between strands B and C of blade 1 in RACK1. Charge reversal mutations of the two basic residues in this conserved turn had earlier been found to abrogate binding of the yeast RACK1 ortholog (Asc1p) to the ribosome (vide supra). The additional detail provided by the crystal structure suggests that, whereas the Lys is orientated towards phosphates on the nearby rRNA backbone, the Arg of the RDK motif engages an Asp residue (D27) on rpS17e. A phenylalanine side chain (F30) on rpS17e, proximal to this Asp, inserts into the mouth of the RACK1 tunnel to form extensive packing interactions against aromatic side chains lining the inner rim formed by the RACK1 D-A and B-C loops. Contact between RACK1 and $\mathrm{rpS} 16 \mathrm{e}$ is less extensive and focused almost entirely on the edge of blade 1 . The third ribosomal protein, rpS3e, engages RACK1 with an extended $\mathrm{C}$-terminal strand that runs diagonally across the edge of blade 4 and terminates in contact with the C-D loop of blade 5 . This strand is not defined in a crystal structure for the yeast ribosome at $4.15 \AA$ resolution and adopts a rather different trajectory across blades 4 and 5 in a model derived from a cryo-EM map of the ribosome at $6.1 \AA$ resolution $[83,89,90]$.

The ribosome binding mode for RACK1 established through the recent cryo-EM and X-ray diffraction studies indicates that the top face of the RACK1 propeller, as presented in Figure 2, is fully blocked when RACK1 is bound to the ribosome. In contrast, access to the reverse face of RACK 1 and several of the blade edges is unobstructed, and these surfaces may serve as a platform for recruitment of proteins to the ribosome. One such protein known to be recruited to the translating ribosome is PKC $\beta$ II [91-93]. Competition experiments with peptide sequences derived from WD-repeats 3 and 6 suggest that these regions of RACK1 contribute to the PKC $\beta$ II binding interface [92,93]. Significantly, both loci are accessible in the established ribosome-bound RACK1 structures. Thus, a mammalian RACK1 sequence (99-RRFVGHTKDV-108) corresponding to the outer $\beta$-strand of blade 2 and D-A loop into blade 3 disrupts association of RACK1 and PKC [92]. This sequence, although located proximal to the rRNA of the $40 S$ subunit (Figure 9), has significant surface exposure. Remarkably, sequences from WD6 that are implicated in PKC binding include both $\beta$-strands A (234-DIINALCF-241) and C (255-SIKIWD-260) of blade 6 [42-44,94-96]. Direct contact with residues in these strands can only reasonably occur by intercalation of structural elements from PKC between propeller blades 6 and 7 or, as has been proposed by others, [46] through the peeling off of the outer strands in blade 6 to allow hybridisation with surrogate strands from PKC. The sequence extension between blades 6 and 7 that forms the RACK1 knob may be important in providing flexibility for the structural transition required to accommodate PKC by either of these modes. This knob structure is bound close to rRNA and rp17e in the established $40 \mathrm{~S}$ structures, but mutagenesis and sequence deletion studies indicate that it is not actually essential for binding of RACK1 to the ribosome, at least in the case of yeast [79]. Further work is required to provide a detailed structural understanding of the interaction between PKC and RACK1 and this should include consideration of the role of the RACK1 knob.

A very recent and exciting development in regards to RACK1 structure has been the acquisition of an X-ray crystal structure for the yeast protein, Asc1p, as a homodimer [82]. This new structure has revealed a previously unprecedented mode of $\beta$-propeller dimerisation involving blade hybridisation. Specifically, $\beta$-strands B and $C$ in blade 4 are extruded from the upper face of the propeller as an extended loop for each of the protomers in the dimeric assembly. The remaining strands (A 


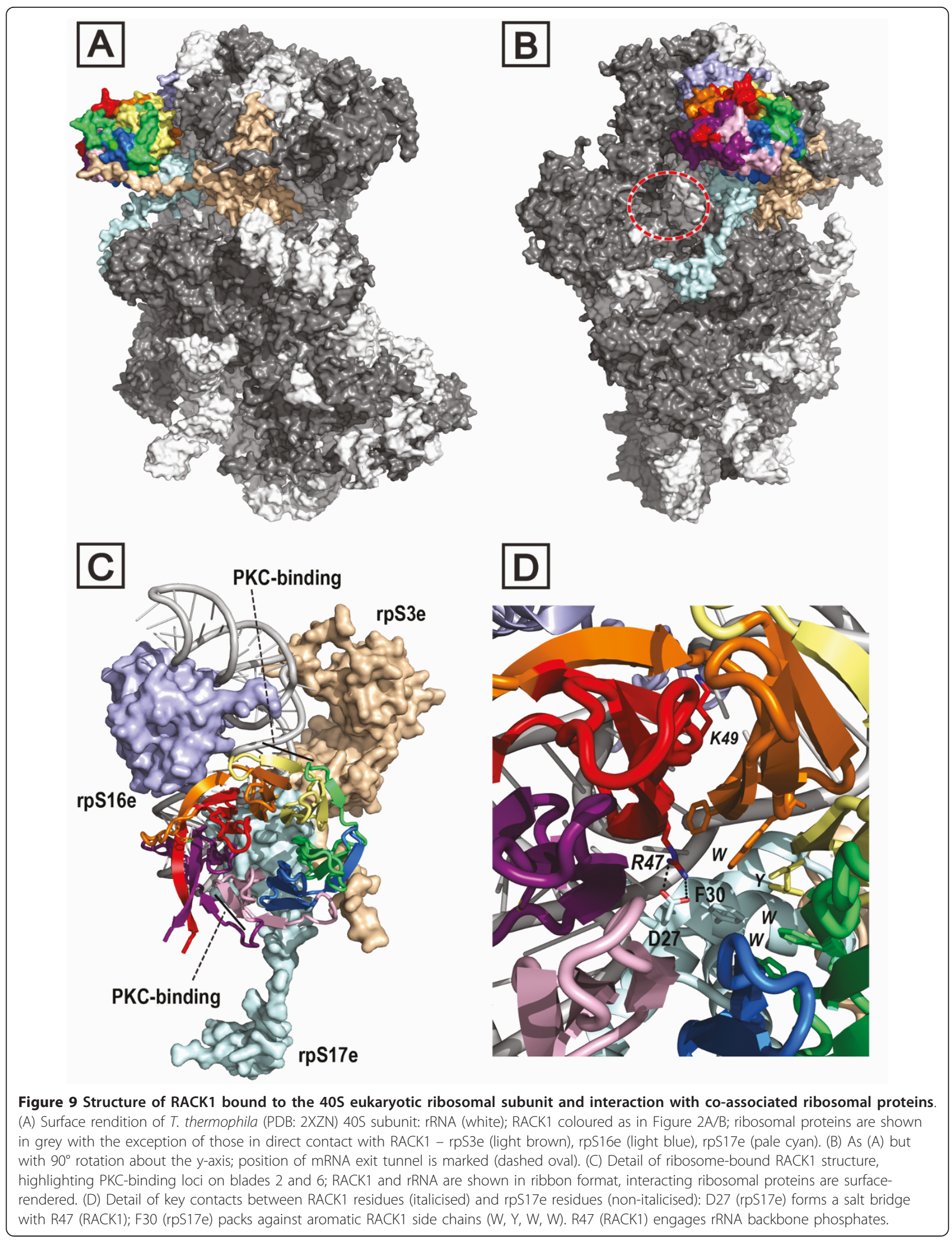


and D) from blade 4 stay within the propeller core but now hydrogen bond directly to one another. Thus, in effect strand D migrates radially inwards to take the position that the extruded strand B ordinarily occupies in the monomeric protein. The two RACK1 protomers then dimerise by hybridisation of the blade $4 \mathrm{D}$-strands, forming a shared four-stranded antiparallel $\beta$-sheet in the format, Protomer-A-D:D-A-Protomer. This mode of dimerisation also brings the blade 3 edges of each protomer sufficiently proximal to one another to hydrogen bond, forming an extended eight-stranded $\beta$-sheet. Remarkably, the extrusion-hybridisation mode of dimerisation centred on blade 4 causes little perturbation in the rest of the protein structure, and the protomers in the dimeric assembly superimpose tightly onto the structure of the monomeric RACK1 protein over the blades not directly involved in dimerisation. The emerging picture for the RACK1 homodimer provides important new insights into the potential interactions between RACK1 and its partner proteins. Firstly, it accounts for the capacity of RACK1 to simultaneously scaffold the NMDA receptor and Fyn (vide infra), where both of these proteins target overlapping binding loci on RACK1. Secondly, the model shows how buried sequences within the core propeller blades may potentially be exposed by extrusion to provide binding surfaces that are not exposed in the monomeric state. The model is particularly significant in relation to the association of PKC (discussed above), where one model for the interaction involves $\beta$-strand swapping between RACK1 and the $\beta$-sandwich C2 domain of the kinase. The RACK1 homodimer structure provides the first direct evidence that such strand extrusion-insertion mechanisms may indeed be important for the interaction of RACK1 with its partners, and, if this is applicable to the binding of PKC $\beta I I$, that such mechanisms may occur with blades other than blade 4 alone.

\section{RACK1 and Signaling}

\section{RACK1 and PKC}

As detailed above, RACK1 was first described as a PKC $\beta$ II anchoring protein [42], and has since been extensively studied in relation to PKC signaling [46,97]. RACK1 binds activated PKC $\beta$ II and the interaction serves to stabilize the active conformation of the kinase $[42,45,60]$ (Figure 3). In addition, RACK1 serves as a PKC $\beta$ II shuttling protein, enabling the kinase to phosphorylate its substrate at the appropriate site [60] (Figure 2). Although most of the studies are focused on the interaction of RACK1 with PKC $\beta$ II isoform, several other PKC isoforms bind RACK1 upon activation $[46,98,99]$. In addition, the RACK1/PKC partnership was suggested to be intrinsically linked and PKCs have been shown to regulate RACK1 expression in cardiac myocytes [100]. As well as stabilising PKC activity, RACK1 introduces activated PKC to new signaling proteins and pathways. These signaling proteins may be directly scaffolded by RACK1 or RACK1 may shuttle its cohort of bound PKC to particular cellular locations and anchor a subset of activated PKC at specific receptor sites. For example, RACK1 was shown to scaffold the MAP kinase (MAPK), Jun N-terminal kinase (JNK) and various $\mathrm{PKC}$ isoforms $(\alpha \beta \gamma)$ upon stimuli leading to PKC phosphorylation of JNK [101]. Thus, RACK1 allows the cross-talk between the PKC and MAPK pathways.

Recently, very exciting data published by the Lebel group suggests that depletion of Werner syndrome, RecQ helicase-like (WRN) protein in the nucleus causes RACK1 to move out of the nucleus and to collocate with PKC $\beta I$ and PKC $\delta$ [102]. This suggests that PKC may also function as a 'sink' for RACK1 in the cytoplasm, preventing RACK1 from going to the nucleus non-specifically. The interaction between RACK1 and PKC family members in the nucleus has also been reported however. Specifically, RACK1 and PKC $\alpha$ are recruited in a circadian manner into a nuclear brain and muscle aryl hydrocarbon receptor nuclear translocator 1 (BMAL1) complex during the negative feedback phase of the cycle [103]. This finding suggests that PKC $\alpha$ is rhythmically activated during this process and that both RACK1 and PKC $\alpha$ are an integral part of the oscillatory mechanism. Finally, the interaction between RACK1 and PKC isozymes plays a role in development [104], as discussed in section 5.1.

\section{RACK1 and the CAMP/PKA pathway}

The cAMP/PKA signaling pathway is also tightly linked to RACK1 [29,56,105-107]. Specifically, cAMP is hydrolysed through the action of CAMP phosphodiesterases (PDEs) [108], and RACK1 interacts with phosphodiesterase isoform PDE4D5 [107,109,110]. Interestingly, RACK1 and the scaffolding protein $\beta$-arrestin compete for binding to PDE4D5 [109]. Furthermore, and as detailed in section 5.2., RACK1 serves as the molecular bridge linking the Focal Adhesion Kinase (FAK) to PDE4D5 to control cell polarity $[111,112]$. In addition, we previously reported that upon activation of PKA by the adenylate cyclase forskolin, or the pituitary adenylate cyclase activating peptide (PACAP), RACK1 translocates to the nucleus where it mediates the expression of the brain-derived neurotrophic factor (BDNF) [56,106] (Figure 4). Finally, the activation of the cAMP/PKA pathway in hippocampal neurons also leads to the dissociation of RACK1 from its binding partners Fyn kinase and the NR2B subunit of the NMDAR, leading to the phosphorylation of the subunit by Fyn, and to enhancement of the channel's activity $[49,56]$ (Figure 5A) (see also sections 3.3 and 3.4.2). 


\section{RACK1 and the Src family of non-receptor protein tyrosine kinases}

RACK1 plays an inhibitory role with the Src family of non-receptor protein tyrosine kinases (PTKs), specifically with Src and Fyn. Thus, RACK1 interacts with Src and Fyn respectively in cultured cancer cells and in neurons, and this interaction inhibits the activity of the kinases, suggesting that RACK1 plays an inhibitory role on Src and Fyn kinase's function [29,49,57,61,113,114]. Suppression of Src activity by RACK1 is central to the regulation of the growth of colon cells [114] and a new report suggests that by inhibiting Src activity, RACK1 stabilises E-cadherin and catenins at cell-cell contacts [115]. The release of RACK1 from Src is mediated by IGF-I [113], and the release of RACK1 from Fyn is mediated by activation of the cAMP/PKA pathway [56], resulting in the activation of both kinases (see also sections 5.3 and 6.2).

\section{RACK 1 and transmembrane receptors}

RACK1 interacts with cytoplasmic tails of several receptors including the Insulin-like Growth Factor Receptor I (IGF-IR), $\beta$-integrin receptor, the common beta-chain of the IL-5/IL-3/GM-CSF receptor [116], type I interferon receptor [117], inositol 1,4,5-trisphosphate receptors (IP3R) when at the cell membrane [118], the muscarinic M2 receptor [119], the adiponectin receptor [120] the androgen receptor [121], as well as several ion channels. As described below, the interaction of RACK1 with intracellular domains of transmembrane receptors results in the positive or negative regulation of receptor function.

\section{RACK1 and receptor tyrosine kinases}

One of the best studied receptor tyrosine kinase (RTK)/ RACK1 associations is the one between RACK1 and the IGF-IR [76,77]. RACK1 interacts with the IGF-IR in a wide variety of cells and the interaction site has been mapped to the C-terminus of the IGF-IR. RACK1 also interacts with the closely related Insulin receptor $[77,122]$. At the IGF-IR, RACK1 recruits a series of proteins including the adaptor proteins, Shc and IRS-1/2, the phosphatase, Shp2, and the transcription factor, STAT3 [77,113,122]. In doing so, RACK1 builds protein complexes to facilitate signaling downstream of the IGFIR. RACK1 also binds the $\beta$ subunits of integrin [123] and integrates and facilitates signaling between the IGFIR and integrins during tumour cell migration $[76,77,124]$. This is mediated in part by the serine/threonine phosphatase PP2A as RACK1 binds PP2A and $\beta 1$ integrin in a mutually exclusive manner $[58,59]$. In bridging the IGF-IR and $\beta 1$ integrin into one complex, RACK1 facilitates the IGF-I and adhesion-mediated recruitment of other proteins to the complex to promote cell migration. Binding of RACK1 to integrins also promotes the engagement of survival signaling pathways [125], the MAPK pathway [126] and the recruitment of several PKC isoforms [127-129].

\section{RACK1 and ion channels}

RACK1 is highly expressed in the CNS, mainly in neurons, during development and also throughout the adult brain, where it is localized to the neural cell bodies and dendrites $[71,86]$. In the CNS, RACK1 interacts with the cytoplasmic tail of ligand-gated and ion-gated channels and plays an important role in the regulation of the channels' functions. Specifically, RACK1 binds the cytoplasmic domain of the $\beta 1$ and $\beta 3$ subunits of the $\mathrm{GABA}_{\mathrm{A}}$ receptor $\left(\mathrm{GABA}_{\mathrm{A}} \mathrm{R}\right)[96,130]$. The interaction between RACK1 and the $\mathrm{GABA}_{\mathrm{A}} \mathrm{R}$ plays an important role in facilitating the phosphorylation of the $\mathrm{GABA}_{\mathrm{A}} \mathrm{Rs}$ by $\mathrm{PKC} \beta \mathrm{II}$, thereby modulating $\mathrm{GABA}_{\mathrm{A}} \mathrm{R}$ function in response to the activation of muscarinic acetylcholine and the serotonin receptors [96,130,131].

RACK1 also plays an important role in regulating the function of the NMDAR. In the hippocampus and the dorsal striatum, RACK1 interacts with the cytoplasmic tail of the NR2B subunit of the NMDAR and simultaneously with the kinase, Fyn [49]. This simultaneous interaction allows Fyn to be localized in close proximity to its substrate, NR2B (Figure 5). However, as long as RACK1 is present in the complex, Fyn cannot phosphorylate the subunit [49]. Activation of the cAMP/PKA pathway leads to the dissociation of RACK1 from NR2B and Fyn $[29,56]$. Once RACK1 is removed from the NMDAR, Fyn is then free to phosphorylate NR2B, which in turn results in an increase in the activity of the channel $[29,49,57]$ (Figure 5A). Interestingly, although the three proteins are expressed throughout the brain, the compartmentalization of Fyn to the NR2B subunit of the NMDAR by RACK1 is detected in some brain regions but not others. Specifically, the tri-molecular complex is detected in the hippocampus and dorsal striatum but is not found in the cerebral cortex or the ventral striatum [49,55-57] (Figure 5B, C). Furthermore, the compartmentalization of Fyn in close proximity to, or away from, the NMDAR bears functional consequences and provides the molecular mechanism underlying the difference in the sensitivity of the NMDAR to alcohol in these brain regions $[55,57]$ (see also section 6.2).

Finally, RACK1 has been pulled out in a yeast 2hybrid screen with the cytoplasmic tail of the large conductance $\mathrm{Ca}^{2+}$ activated potassium (BK) channel [132]. RACK1 was shown to slow the activation of the channel [132], although the functional experiments were conducted in Xenopus Oocytes and must be confirmed in a more physiologically relevant system. Nevertheless, this 
study serves as an example of the ability of RACK1 to interact with ion-gated channels as well.

\section{RACK1 and Examples of Other Interacting Proteins \\ RACK1 and the Androgen Receptor}

RACK1 has been shown to interact with the androgen receptor (AR). In binding to the AR, RACK1 mediates translocation of the receptor into the nucleus [121], and also facilitates the cross-talk of the AR with other kinases [133]. Specifically, the recruitment of Src to ARbound RACK1 facilitates the phosphorylation of the AR on tyrosine residues and regulates its transcriptional activity [133].

\section{RACK1 and 14-3-3}

Very recently, using a proteomics strategy, we identified the scaffolding protein $14-3-3 \zeta$ as a binding partner of RACK1 (Neasta et al. 14-3-3/RACK1, in revision). We found that the interaction between the two scaffolding proteins is direct and does not require the prior phos-

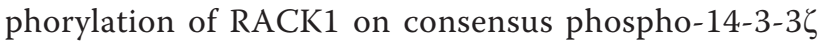
binding sites. Using a RACK1-derived peptide array approach, we identified two putative binding sites for 14-3-3ל located within the WD2-3 and WD4-5 propeller blade regions of RACK1. We found further evidence to suggest that $14-3-3 \zeta$ is necessary for the shuttling of RACK1 to the nucleus and to the subsequent activation of $B D N F$ transcription in response to activation of the cAMP/PKA pathway (Neasta et al., 14-3-3/RACK1 in revision). These findings provide the first intriguing example that the interaction between two multifunc-

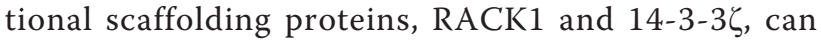
provide a multiprotein signaling platform to tether signalosome.

\section{RACK1 and acetylcholinesterase}

RACK1 interacts with the stress-induced splice variant of acetylcholinesterase (AChE-R) ([134]. The interaction between AChE-R and RACK1 leads to the recruitment of PKC $B I I$ in the CA1 and CA3 regions of the hippocampus, as well as the basolateral amygdala [134]. Furthermore, peripheral anionic site (PAS) inhibition of $\mathrm{AChE}$ in primary hippocampal neurons led to the redistribution of RACK1, decreased Fyn expression and NR2B insertion into the synaptic membrane, resulting in spontaneous excitatory post-synaptic currents (sEPSCs) [135].

\section{RACK1, Postranslational Modifications and Subcellular Compartmentalisation Post-translational modifications}

In response to stress, RACK1 is sequestered into stress granules and inhibits apoptosis by suppressing stress- responsive MAPK pathways [136] Elegent studies carried out by Ohn et al, [137], have revealed that in response to arsenite-induced stress, RACK1 is reversibly modified by $\mathrm{O}$-linked $\mathrm{N}$-acetylglucosamine (O-GlcNAc) and moves from polysome-containing fractions to monosome-containing fractions of the cell. This study also indicates that when modified by O-GlcNAc, RACK1 moves to ribosomal subunit-containing fractions where it associates with the translational machinery and promotes stress granule assembly. Little is known about other post-translational modifications of RACK1 apart from phosphorylation which is emerging as an important factor that modulates the binding of proteins to RACK1. RACK1's sequence contains six tyrosine residues: Tyr-52 (located at the boundary of WD1 and WD2), Tyr-140 (WD 4), Tyr-194 (WD5), Tyr-228 and Tyr-246 (WD 6), and Tyr-302 (WD7). Phosphorylation of RACK 1 on Tyr- 52 by c-Abl mediates the interaction with FAK [124], which is required for cell adhesion and cell migration while phosphorylation/dephosphorylation of Tyr-302 in WD7 of RACK1 regulates the mutually exclusive association of RACK1 with PP2A and $\beta 1$ Integrin [58,59]. Phosphorylation of RACK1 on Tyr-246 is required for the binding of Src kinase to RACK1 [138]. The interaction between RACK1 and Src is essential for the regulation of Src activity during the cell cycle $[114,139]$. RACK1 is also a substrate of Src. Specifically, Src phosphorylates RACK1 on Tyr-228 and strong evidence suggests that Src phosphorylates RACK1 on Tyr 246 also [48]. In addition, serine phosphorylation of RACK1 is also reported. Phosphorylation of RACK1 on Ser-146 promotes its dimerization which is required for the degradation of HIF-1 $\alpha$ [140]. Taken together, these studies suggest that RACK1 is modified by signaling pathways which is important for protein binding and RACK1 location.

\section{Subcellular localization and translocation}

RACK1 immunoreactivity can be detected in various cellular compartments including the cytosol, endoplasmic reticulum and the nucleus. In neurons, RACK1 is detected in cell bodies and dendrites but not in axons $[71,86]$. In addition, translocation of RACK1 from one subcellular location to another has been shown to mediate various cellular responses following a stimulus. For example, in response to PKC activation, RACK1 accompanies PKC $\beta$ II to its site of action [60] (Figure 2), and as mentioned above, upon cellular stress induced by hypoxia or heat shock, RACK1 is sequestered into cytoplasmic stress granules preventing the activation of a stress-responsive MAPK pathway, which in turn leads to cell survival instead of cell apoptosis [136]. Moreover, the activation of the cAMP/PKA pathway in various types of cells, including neurons, induces RACK1 
translocation to the nucleus $[56,106,141,142]$ subsequently leading to the transcription of the brain-derived neurotrophic factor $(B D N F)[56,57,106,143]$ and (Neasta et al 14-3-3/RACK1 in Revision) (Figure 4). The RACK1 sequence does not contain known organelle localization motifs, or N-terminal lipid modification sites; nor does the sequence contain nuclear entry or nuclear export signals. In addition, there are no conclusive reports that the subcellular location of RACK1 is controlled by posttranslational modification of RACK1 itself. Thus, the movement of RACK1 around the cell is most likely influenced by the particular cohort of proteins associated with RACK1 at any one time. An example, of such interacting protein is 14-3-3 which enables RACK1 to be transported to the nucleus in response to the activation of the cAMP/PKA pathway (Neasta et al 14-3-3/ RACK1 in Revision).

\section{RACK1 in the nucleus}

As detailed above, activation of the cAMP pathway in various types of cells, including neurons induces RACK1 translocation to the nucleus, subsequently leading to the transcription of several genes including $B D N F$ $[56,106,141,143]$ and (Neasta et al 14-3-3/RACK1 in Revision). In relation to $B D N F$ transcription, using adenovirus-mediated siRNA delivery to knockdown the level of RACK1 in differentiated SHSY5Y cells and hippocampal neurons, we showed that activation of the cAMP pathway results in the association of RACK1 with the promoter IV region of the $B D N F$ gene, leading to an increase in exon IV specific BDNF transcription [106]. RACK1 has been identified in several other complexes in the nucleus. It binds to the RQC domain and the acidic region of WRN and WRN may play an important role in retaining RACK1 in the nucleus [102]. Ki-1/57, a Ser/Thr protein kinase that interacts with chromo-helicase DNA-binding domain protein 3, forms a tight complex with RACK1 in the nucleus and treatment of cells with the PKC activator, PMA, mediates threonine phosphorylation of $\mathrm{Ki}-1 / 57$ and disrupts the interaction with RACK1 [144]. Finally, RACK1 is also an essential component of systems required for regulating HIF-1 $\alpha$ stability $[54,145]$ and it does so by competing with HSP90 for binding to HIF- $1 \alpha$.

\section{RACK1 and ribosomes}

An exciting development in RACK1 physiology is the realisation that RACK1 has a key role to play in the translation machinery [146]. The identification of RACK1 as a ribosome-associated protein was first made by mass spectroscopy [147], and in recent years RACK1 has become a well-established component of the ribosomal machinery through studies with ribosomes from yeast [83,84,89,148-151] and fungi [88], from unicellular algae [152] and plants [89,90,153-156] from protozoa [80] and mammals [85,86,137]. As discussed (Part 2), the RACK1 binding site, located on the $40 \mathrm{~S}$ subunit of the eukaryotic ribosome, is now well defined by several structural studies.

Although ribosome-bound RACK1 might directly regulate translation per se, its function as a ribosomal protein is likely linked to its capacity to recruit a particular cohort of RACK1-associated proteins such as activated PKC $\beta$ II. Indeed, PKC-mediated translational control has recently been shown to be dependent upon RACK1, and a RACK1-derived peptide that disrupts PKC $\beta I$ II binding to RACK1 or down-regulation of RACK1 with siRNA impairs PKC-stimulated translation [92]. The action of PKC $\beta I$ I in stimulating translation is thought to arise, at least in part, from its phosphorylation of eukaryotic initiation factor 6 (eIF6) bound to the $60 \mathrm{~S}$ ribosomal subunit. Specifically, assembly of the ribosome by joining of $40 \mathrm{~S}$ and $60 \mathrm{~S}$ subunits is a rate-limiting step in translation, and PKC $\beta$ II-mediated phosphorylation of a carboxy terminal serine (S235) in eIF6 triggers release of the initiation factor to facilitate this [91]. Identification of the ribosomal binding site for RACK1 has therefore suggested a model for ribosome assembly in which phosphorylation of eIF6 by PKC occurs on the 60S subunit as a result of an interaction with eIF6 and PKC bound to a nearby $40 \mathrm{~S}$ subunit via RACK1 [84]. RACK1 is also known to bind eIF6 directly, although the loci on RACK1 for this interaction have not yet been defined and it is unclear whether phosphorylation of eIF6 by PKC involves simultaneous association of both enzyme and substrate initiation factor on the ribosome-bound RACK1.

In contrast to its role in promoting translation, other studies suggest that RACK1 may act at the ribosome to repress gene expression [148,157]. Specifically, very recently it has been shown that RACK1 interacts with components of the microRNA-induced gene silencing complex, contributing to recruitment of the complex to the site of translation and suggesting that RACK1 facilitates a post-initiation mode of miRNA-mediated gene repression [157]. RACK1 may also be involved in translation arrest, and its binding at the $40 \mathrm{~S}$ subunit has been shown to be essential for nascent polypeptidedependent translation arrest [158]. Finally, it is also feasible that the action of RACK1 at the ribosome may result in varying effects on gene expression by recruiting proteins that regulate translation of specific mRNAs in different ways. For example, Baum et al. suggested that recruitment of the mRNA-binding protein, Scp160p, to the yeast homolog (Asc1p) of RACK1 may influence the translation of specific mRNAs [159]. In addition to affecting the rate of translation of mRNAs, RACK1 is thought to play a role in influencing the location of translation, for example, in neurones [86]. 


\section{RACK1 and Physiological Functions RACK1 and development}

In recent years, a critical role for RACK1 in development has been emerging. For example, in zebrafish, RACK1 affects membrane localization of van gogh-like 2 (Vangl2), and the Vangl2-interacting region of RACK1 has been shown to exert a dominant-negative effect on Vangl2 localization and gastrulation [160]. The interaction between RACK1 and tyrosine-protein kinase-like 7 (PTK7) has also been shown to be a requirement for neural tube closure in Xenopus [161]. In Arabidopsis, where three RACK1 homologs are present, the RACK1 gene products are essential regulators of plant development [162,163]. RACK1 homologs in Drosophilia [164], Aspergillus nidulans [165], Schizosaccharomyces pombe [166] and Trypanosoma brucei [167] have similarly been shown to be central to various stages of the developmental process.

\section{RACK1 and circadian rhythm}

Recent elegant studies by Robles et al. [103] have identified RACK1 as an integral component of the mammalian circadian clock. Their findings suggest that RACK1 and PKC $\alpha$ regulate CLOCK-BMAL1 transcriptional activity [103]. Their findings also indicate that the mechanism of action of RACK1 and PKC $\alpha$ are intrinsically linked and that the function of one is dependent on the other. Although it is well established that RACK1 regulates PKC location $[60,92,134,142]$, this exciting development in RACK1 biology reveals a novel mechanism of action.

\section{RACK1 and cell migration}

The scaffolding of signaling proteins by RACK1 at receptors is particularly important in dynamic processes such as cell migration, cell adhesion and cell spreading $[76,77,113,124]$. All of these processes require the highly regulated converging of transient signaling between receptors. For example, RACK1 was first found to be a mediator of cell spreading by establishing contact with the extracellular matrix and growth factor receptors at adhesion sites [76].

The role of RACK1 as a scaffolding protein is clearly evident during cell migration. Cell migration is a fundamental process required for embryonic development, wound healing and immune responses, and the components of cell migration are functionally conserved in evolution. The failure of cells to migrate, or indeed their migration to the wrong location, gives rise to serious life threatening consequences such as defective brain development, a malfunctioning immune system and leads to the materialization of cancer. Understanding cell migration presents a considerable challenge because it results from the coordinated activity of several individual intraand extracellular component processes. These processes include several signaling pathways, and require significant and well-orchestrated cross-talk between cell surface receptors and elements of the cell cytoskeleton. RACK1 is essential for cell migration, and the protein binds to many components of the cell migration machinery including kinases, phosphatases and the cytoplasmic domains of cell surface receptors [46,47]. RACK1 is located in areas of cell protrusion that are rich in paxillin $[168,169]$ and can increase the phosphorylation of FAK [169]. The interaction of RACK1 with $\beta 1$ and $\beta 2$ integrins and Src regulates cell adhesion and cell spreading $[123,168]$. RACK1 has been reported to bind to components of the cell cytoskeleton $[128,170]$. The identification of proteins such as these as RACK1 partners has led to the establishment of RACK1 as a key regulator of Focal Adhesion assembly (Figure 10). Focal adhesions are large dynamic macromolecular assemblies with both mechanical components and cell signaling components [171-175]. Specifically, focal adhesions are the mechanical link between the cell and the extra cellular matrix (ECM), that are formed after integrins are clustered on the cell surface. Integrin clustering is sufficient to promote the phosphorylation of FAK on Tyr397. This in turn generates a binding site for the Src

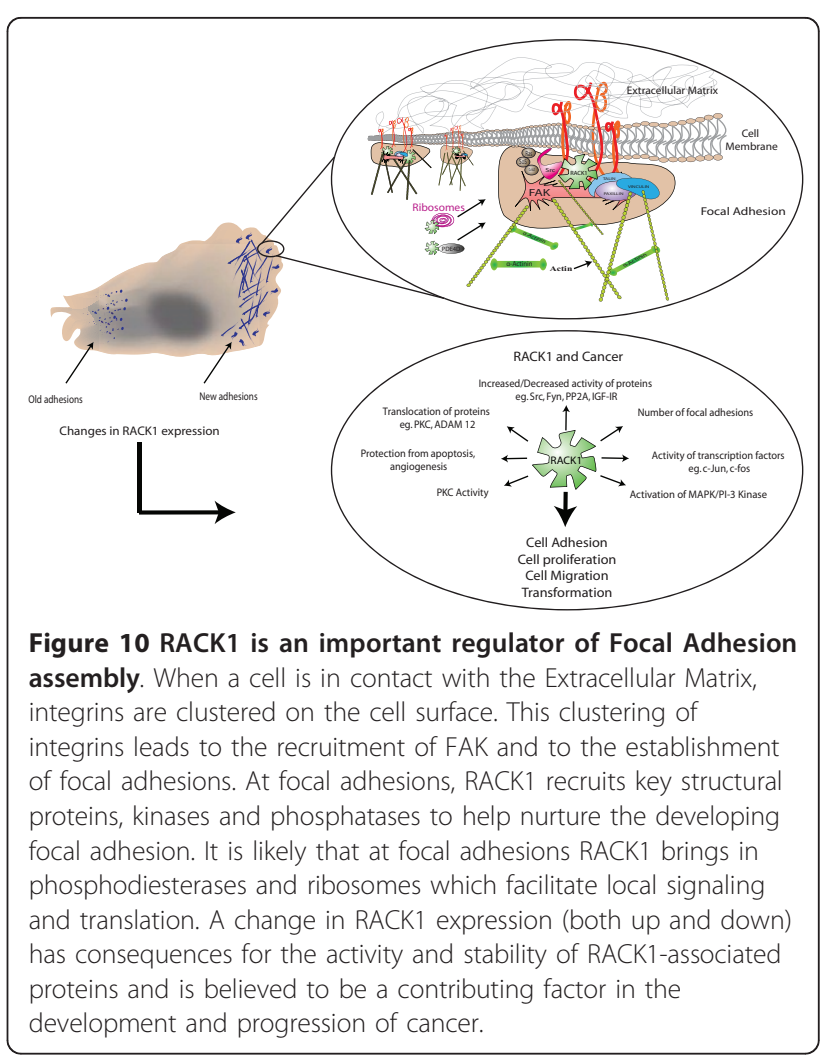


homology 2 (SH2) domain of Src Family protein tyrosine kinases (Src-family PTKs). The recruitment of Srcfamily PTKs to FAK is dependent on the initial autophosphorylation of Tyr-397 and results in the phosphorylation of FAK at secondary sites to ensure full activation of FAK. This correlates with an increase in kinase activity and the ability of FAK to cooperate with multiple signaling pathways through its direct interaction with other non-receptor tyrosine kinases, cell surface receptors, cytoskeletal proteins and other adaptor proteins. FAK is widely regarded as being the convergence point of growth factor and integrin signaling [176,177], yet how FAK phosphorylation is regulated within the growth factor and integrin network is not fully understood. Nevertheless, the phosphorylation status of FAK clearly regulates cell adhesion and cell migration in response to growth factors, integrin stimulation and components of the extracellular matrix. RACK1 is essential for FAK's function as it scaffolds the kinase for activation by both IGF-I and adhesion signals [124] and the binding locus for FAK on RACK1 has been mapped to Tyr-52 in WD2 of RACK1 [124] and the interaction site of RACK1 on FAK was subsequently identified [112]. Suppression of RACK1 expression disrupts FAK activity, cell adhesion and cell spreading $[113,124,169]$, two essential steps in the cell migration process, by the interaction of RACK1 with FAK and by the ability of RACK1 to regulate FAK activity. In addition, recent studies suggest that attenuation of RACK1 expression suppresses VEGF-mediated cell migration by disrupting the path between VEGF, the PI3K pathway and Rac1 [178]. RACK1 (and RACK1A) is known to interact with several components of the Rac1 complex that are involved in cell migration $[179,180]$. Cell migration is dependent on the response to chemoattractant gradients, and in Jurkat cells RACK1 interacts with G $\beta \gamma$ at the leading edge of cells [181]. In this system, RACK1 inhibits cell migration and overexpression of full length RACK1 or truncation mutations that retain the $G \beta \gamma$ binding, actually inhibit cell migration [181]. There are other reports suggesting that RACK1 inhibits cell migration [128] but under most circumstances, RACK1 facilitates cell migration. A large part of what RACK1 does in cell migration, at least in adherent cells, is mediated by its ability to bind to a series of kinases and phosphatases that affect the phosphorylation and subsequent activity of other RACK1 binding partners or proteins in complexes where RACK1 is found. RACK1 interacts with several $\mathrm{PKC}$ isoforms during cell migration including $\mathrm{PKC} \beta$ [170] and $\mathrm{PKC} \varepsilon$ [127]. Activation of the PKC signaling pathway also enhances the interaction between RACK1 and Src [138]. Src tyrosine kinase phosphorylates RACK1 and phosphorylation of RACK1 is required for Src binding to RACK1 via its SH2 domain [48]. Src is a well-known regulator of cell adhesion, cell spreading and cell migration $[61,62,114,168]$. Src activity is inhibited by the binding of RACK1 but RACK1 can transport Src to specific cellular compartments where Src can function. In fibroblasts and epithelial cells, the interaction between RACK1 and Src is disrupted by IGF-I stimulation of the IGF-IR signaling pathway [113]. This results in the release of now active Src at a specific location and is an example of how RACK1 can regulate the local activation of proteins. The regulation of Src activity by RACK 1 is also required for modulating paxillin during cell migration [182], for regulating Sam68 and p190RhoGAP signaling [183], to control cell protrusion during cell migration [168] and for regulating cell cycle checkpoints $[62,114,139]$. The dynamic interaction between RACK1 and Src is also required for regulation of the phosphorylation and function of the Androgen receptor [133]. There are now data suggesting that the interaction between RACK1 and Src goes beyond regulating cell adhesion and cell migration and Mamidipudi et al, have shown that the interaction has a pro-apoptotic function [184]. The interaction of RACK1 with phosphatases during cell adhesion is equally important and mounting evidence suggests that RACK1 receives signals to recruit phosphatases that dismantle specific signaling pathways and cytoplasmic support systems such as focal adhesions $[58,124,185]$. In IGF-IR signaling, RACK1 promotes IGF-I-mediated cell migration by regulating the formation of a RACK1-IGF-IR and $\beta 1$ integrin complexes, which is mediated by the mutually exclusive association of RACK1 with PP2A and $\beta 1$ integrin $[58,59]$. In pancreatic cells, RACK1 and PP2A form a complex with IRE1 $\alpha$ in a signaling pathway that regulates insulin production [186]. In addition, RACK1 and phosphatases are involved in cell migration in other systems. Fo example, in the retina, retinal ganglion cell axons are guided by signaling pathways that are regulated by an interaction between RACK1 and PTP $\mu$ [185,187-189].

\section{RACK1 in Disease}

Since its discovery, RACK1 has been associated with various aspects of diseases. Alterations in RACK1 homeostasis is associated with brain developmental disorders [161], heart failure [99], pulmonary arterial hypertension [190], renal failure [191], muscle atrophy [192] and dysfunctional sperm development [193], as well as cancer and addiction (detailed in sections 6.1 and 6.2). In addition, altered RACK1 expression has negative consequences for the properties and activity of RACK1 binding partners. The association of RACK1, PKC $\beta I$ and a variant of the acetylcholinesterase AChE has been implicated in stress-induced behaviors [134] (see also section 6.2). Increased RACK1 expression has also been 
observed in the frontal cortex of patients with bipolar disorder [194], while decreased RACK1 expression is reported in the cortex of Down syndrome patients [74]. In addition, RACK1 levels are significantly reduced in aged rats [195], and decreased RACK1 expression is reported in post-mortem brains of Alzheimer's disease (AD) patients [72,73]. However these changes were not found in another study, which compared the levels of RACK1 in AD patients and age-matched controls [196]. Nevertheless, the pathophysiology of AD patients also highlights defective PKC activity and localisation which correlates with decreased RACK1 expression [197]. PKC and muscarinic receptor signaling are intrinsically linked, and amyloid- $\beta$ impairs the regulation of PKC and GABAergic signaling. Overexpression of RACK1 has been shown to restore the regulation of these processes [198].

Several reports suggest a role for RACK1 in the immune system. Specifically, studies carried out in T Jurkat cells indicate that RACK1 regulates directional cell migration [181] while other reports suggest that RACK1 regulates $T$ cell apoptosis [199]. In Rice, RACK1A functions in innate immunity by interacting with the GTP form of Rac1 [179] and having a central role in the production of reactive oxygen species in response to infection. Because of its role in several signaling pathways, it is not surprising, therefore, that RACK1 is hijacked by viruses to facilitate viral replication [200-202].

\section{RACK 1 and cancer}

Many reports indicate that RACK1 plays an important role in cancer progression and that its expression is altered during angiogenesis and in many human carcinomas. Specifically, RACK1 expression is being assessed as a prognostic indicator in breast cancer [203,204], where increased RACK1 expression is strongly related to advanced clinical stage [205]. In pulmonary adenocarcinomas, increased RACK1 expression is associated with pathological stage and tumor size and is also a potential diagnostic marker [206]. In contrast, some reports suggest that RACK1 expression is reduced in breast cancer [207]. In addition, RACK1 may protect cells from apoptosis in breast cancer [204,208]. RACK1 is upregulated in hepatocellular carcinoma where it increases the translocation of A Disintegrin And Metalloprotease 12 (ADAM12) to the plasma membrane in response to PKC activation [209] and it is upregulated in metastatic melanoma, where it amplifies PKC $\alpha$ and PKC $\beta$ activity [210]. In melanoma, constitutive activation of the MEKERK signaling pathway leads to elevated c-Jun activity and increased the transcription of RACK1 [211]. RACK1 is also implicated as a key player in ovarian cancer [212], prostate cancer [188] and in cancers caused by pathogens such as human papillomavirus 16 (HPV 16) [213] and Helicobacter pylori [214].

There are several mechanisms by which RACK1 contributes to the progression of cancer. Firstly, RACK1 is upregulated during angiogenesis [215] where it promotes activation of the PI3K/Akt/Rac1 pathway [178] and regulates HIF-1 transcriptional activity [216,217]. RACK1 also plays an important role in cell proliferation, cell adhesion and cell migration, which are all essential components of transformation as described in section 5.3. The interaction between RACK1 and FAK is constitutive and FAK phosphorylation on the RACK1 scaffold is mediated by the IGF-IR [124]. The interaction between RACK1 and FAK is found at nascent adhesions and is required at the leading edge of polarized cancer cells to sense direction. RACK1 also brings FAK and PDE4D5 together which strongly suggests that adhesion signaling and cAMP signaling are linked in cancer [111,112]. At adhesion sites, RACK1 recruits paxillin $[168,169]$, integrins and Src to regulate cell adhesion and cell spreading [113,123,124,168], $\beta$-tubulin [218] and other components of the cell cytoskeleton [170]. Thus, in cancer, RACK1 becomes a focal point for transformation signaling (Figure 10). RACK1 recruits ribosomes and PKC (discussed above) and scaffolds central components of the MAPK pathway [126] and the PI3K pathway $[76,77,113]$. As well as this, RACK1 scaffolds a host of other different kinases and phosphatases, and the activity of several of these proteins is altered in cancer. All of these proteins, signaling pathways and protein complexes require tight regulation. Subtle changes in the protein expression (both up and down) of a fundamental protein such as RACK1 can be expected to have dramatic consequences on the regulation of these key pathways and therefore on the development and progression of neoplastic disease.

\section{RACK1 and addiction}

Addiction is a costly, devastating psychiatric disorder. The disease manifests itself in the intake of the drug regardless of the negative consequences, and is associated with tolerance, dependence, withdrawal, relapse and craving [219]. Altered levels and compartmentalization of RACK1 was reported by us and others to be linked to exposure to drugs of abuse. Specifically, changes in RACK1 levels have also been described in response to the treatment of rodents acutely and chronically with morphine. Escriba et al. found that acute treatment of rats with morphine results in increased RACK1 levels in the frontal cortex, whereas chronic treatment with morphine led to a decrease in the level of RACK 1 in this brain region [220]. The authors also report that changes in RACK1 levels paralleled with changes in the levels of PKC $\alpha$ and PKC $\beta$ [220]. In 
contrast, Wan et al. found that chronic treatment of mice with morphine led to an increase in the level of RACK1 in this brain region [221]. Finally, Liu et al. reported that alteration of RACK1 levels result in changes in the rewarding properties of morphine $[222,223]$. In summary, although changes in RACK1 expression are linked to morphine administration, further studies are needed before any conclusions can be drawn.

In addition, over the past several years, we have demonstrated that one of the molecular mechanisms by which alcohol can simultaneously alter several signaling pathways is by altering the cellular compartmentalization of RACK1. Furthermore, we obtained data to suggest that the functional outcomes of the altered localization of RACK1 in the presence of alcohol are diverse, as RACK1 contributes both to mechanisms that underlie but also those that prevent the escalation of behaviors that underlie alcohol addiction. The interest in the potential role of RACK1 in alcohol addiction was initiated with the observation that exposure of several cell lines as well as primary neurons to alcohol results in a dose- and time-dependent translocation of RACK1 to the nucleus [141-143,224]. The nuclear translocation of RACK1 in response to alcohol was shown to be dependent on the activation of the cAMP/PKA pathway [141]. Interestingly, prolonged incubation of cells with alcohol (12-48 hrs) results in the gradual distribution of RACK1 out of the nucleus, which was resistant to an acute challenge of alcohol [143,224]. These results suggest a cellular alcohol tolerance leads to altered compartmentalization of RACK1. Furthermore, as a result of the nuclear localization of RACK1 in response to acute alcohol exposure, the translocation of active PKC $\beta I$ Is inhibited [142], and the transcription of several genes are induced [141-143,224].

Of great interest is the observation that the expression of the growth factor BDNF is increased in response to alcohol-mediated RACK1 nuclear localization [143]. Importantly, molecular and behavioral studies suggest that RACK1 and BDNF are part of an endogenous homeostatic pathway that delays or prevents the development of alcohol addiction. Specifically, acute increase of RACK1 protein levels in hippocampal and striatal neurons using the Tat protein transduction approach (Tat-RACK1), led to increases in the levels of BDNF and a similar increase in BDNF expression was observed after systemic injection of the Tat-fusion protein in mice [143]. The systemic administration of mice with Tat-RACK1 resulted in a robust decrease in alcohol but not water consumption in mice in a BDNF-dependent manner [143,225]. Specifically, the activity of TatRACK1 on alcohol consumption was reduced in BDNF heterozygote mice as compared to wild-type mice, and, systemic administration of a BDNF receptor TrkB inhibitor increased alcohol consumption in wild-type controls, but not in BDNF heterozygote mice [143,225]. We also provide data that the inhibitory actions of RACK1 on alcohol intake are localized to the dorsal striatum as infusion of Tat-RACK1 directly into the dorsal striatum of rats reduced rat operant self-administration of alcohol [225]. Finally, we obtained data to suggest that the consequence of RACK1 mediated increase in BDNF expression in response to alcohol is the increase in the expression of the dopamine D3 receptor and Dynorphin which in turn mediate the reduction in the sensitivity of rodents to alcohol [225,226]. Together, these results suggest that RACK1 inhibits alcohol consumption by increasing the expression and secretion of BDNF, and that secreted BDNF counteracts the reinforcing or rewarding effects of alcohol. Thus, the RACK1 and BDNF pathway contributes to cellular and molecular processes that influence the motivation to seek alcohol.

Interestingly, the altered compartmentalization of RACK1 in response to alcohol exposure in specific brain regions also contributes to neuroadaptations that underlie the development of alcohol addiction. As described in section 1.2, in the hippocampus and the dorsal striatum but not in the cerebral cortex or ventral striatum, RACK1 localizes Fyn in close proximity to the NR2B subunit of the NMDAR, but inhibits the ability of Fyn to phosphorylate the channel until the appropriate signal occurs $[29,49,55,57,141]$ (Figure 5A). This specific compartmentalization of Fyn to the NMDAR complex via RACK1 has broad implications for the actions of alcohol on the channel. In the hippocampus, alcohol treatment results in the release of RACK1 from the NMDAR complex in a mechanism that depends on the activation of the cAMP/PKA signaling cascade [57]. The dissociation of the tri-molecular complex in response to alcohol enables Fyn to phosphorylate NR2B [57]. These molecular changes in the hippocampus lead to a reduction in the inhibitory actions of alcohol on channel activity, in rebound potentiation of the activity of the channel when alcohol is washed out, and to the development of acute desensitization to the inhibitory actions of alcohol on the activity of the channel [57]. In the dorsal striatum, RACK1 dissociation from Fyn and NR2B and the phosphorylation of the subunit by Fyn leads to long-lasting long-term facilitation of the activity of the channel [55]. Importantly, this biochemical neuroadaptation in the dorsal striatum is part of a mechanism that underlies excessive alcohol consumption and relapse [55,227].

In summary, the altered compartmentalization of RACK1 in the presence of alcohol in specific brain regions results in diverse physiological consequences that both contribute to, and prevent, the development of behaviors associated with alcohol addiction. 


\section{Summary and Future Perspectives}

Since its identification as an anchoring protein for active $\beta$ IIPKC [42], the number of binding partners and functions for RACK1 have increased exponentially. It is intriguing that a single protein can be involved in such a large number of diverse biological functions. One possibility is that the different intracellular compartmentalization of RACK1 in different cell types and regions allows the scaffolding protein to interact with multiple proteins and to regulate various functions in a cell specific manner (see Figure 10 as an example). Another possibility to explain the multiple functions of RACK1 is that although the protein itself is ubiquitously expressed, its binding partners are not. For example, RACK1 is ubiquitously expressed in the adult mouse brain, however, a much more restricted expression pattern is observed for PKC $\beta$ II $[71,228]$. Interestingly, as described above, RACK1 can be associated with different binding partners in different brain regions. Specifically, although similar type of neurons are found in the hippocampus and cortex as well as in the ventral and dorsal striatum, RACK1 is associated the NR2B subunit of the NMDAR in the hippocampus and the dorsal striatum, [49,55-57] but not cerebral cortex but not in the ventral striatum $[55,57]$. These findings suggest that RACK1 scaffolds different proteins in these brain regions. The reasons for cell type or brain region specificity of RACK1 association with its binding partner is unclear and therefore it would be of great interest to explore this further.

Furthermore, we now know that proteins, such as PP2A and $\beta 1$ integrin, compete for binding to RACK1 $[58,59]$, and that phosphorylation of RACK1 on tyrosine and serine residues is critical for the way in which RACK1 functions during cell adhesion and cell migration $[61,114,124]$. It is thus essential that we gain a better understanding of what determines the hierarchy of protein binding to RACK1 and what signals orchestrate complex formation on RACK1. For example, growth factor and adhesion signaling converge on RACK1 $[76,113,122,124]$, but it of interest to now focus on how other external environmental cues dictate the binding profile and cellular distribution of RACK1 and how RACK1 integrates these signals with such a high degree of specificity and regulation.

Finally, the unique structure of RACK1 and the expansion of knowledge of the protein-protein interactions mediating the binding of RACK1 to partners provide us with a great opportunity to develop new therapeutics by the design and development of peptides, and in the future possibly small organic compounds, which will interfere with specific binding of proteins to RACK1. This will permit subtle manipulation of the activity of specific enzymes, receptors and signaling pathways.

\section{Endnotes}

\section{Footnote 1}

${ }^{1}$ A convenient graphical representation of consensus residues at particular sites within WD-repeats has been given by $\mathrm{Xu}$ and Min [6]. Significant diversity is seen across repeats in WD40 proteins and we refer to 'typical' repeats as ones that preserve the core interactions summarised in Figure 7.

\section{Acknowledgements}

We are grateful to Susan Dwane in the Laboratory of Cellular and Molecular Biology for their assistance and critical review (P.K). The authors would like to thank Marcus Cavness and Carol Webb. This review was supported by the Health Research Board of Ireland HRA/2009/188 (P.K.), the Irish Cancer Society (P.K.), the NIH-NIAAA R01 AA016848 (D.R.), NIAAA (R01AA/MH13438) (D.R.), the Department of the Army, Grant \#W81XWH-05-1-0212 (D.R.), the State of California, for Medical Research on Alcohol and Substance Abuse through the University of California, San Francisco (D.R.). We used PyMOL from W. L. DeLano, DeLano Scientific to create the protein structure images in this work (D.A.).

\section{Author details}

'Department of Chemistry, Heriot-Watt University, Riccarton Campus, Edinburgh EH14AS, UK. ${ }^{2}$ Ernest Gallo Research Center, Department of Neurology, University of California, San Francisco, Emeryville, CA, USA 94608. ${ }^{3}$ Department of Life Sciences, and Materials and Surface Science Institute, University of Limerick, Limerick, Ireland.

\section{Authors' contributions}

$\mathrm{DA}, \mathrm{DR}$ and PK contributed equally to the writing of the manuscript. All authors read and approved the final version of the manuscript.

\section{Competing interests}

The authors declare that they have no competing interests.

Received: 7 August 2011 Accepted: 6 October 2011

Published: 6 October 2011

\section{References}

1. Li D, Roberts R: WD-repeat proteins: structure characteristics, biological function, and their involvement in human diseases. Cell Mol Life Sci 2001, 58:2085-2097.

2. Fong HK, Hurley JB, Hopkins RS, Miake-Lye R, Johnson MS, Doolittle RF, Simon MI: Repetitive segmental structure of the transducin beta subunit: homology with the CDC4 gene and identification of related mRNAs. Proc Natl Acad Sci USA 1986, 83:2162-2166.

3. Neer EJ, Schmidt CJ, Nambudripad R, Smith TF: The ancient regulatoryprotein family of WD-repeat proteins. Nature 1994, 371:297-300.

4. Smith TF: Diversity of WD-repeat proteins. Subcell Biochem 2008, 48:20-30.

5. Smith TF, Gaitatzes C, Saxena K, Neer EJ: The WD repeat: a common architecture for diverse functions. Trends Biochem Sci 1999, 24:181-185.

6. Xu C, Min J: Structure and function of WD40 domain proteins. Protein Cell 2011, 2:202-214

7. Neer EJ: Heterotrimeric $G$ proteins: organizers of transmembrane signals. Cell 1995, 80:249-257.

8. Paoli M: Protein folds propelled by diversity. Prog Biophys Mol Biol 2001, 76:103-130.

9. Sondek J, Bohm A, Lambright DG, Hamm HE, Sigler PB: Crystal structure of a G-protein beta gamma dimer at 2.1A resolution. Nature 1996, 379:369-374.

10. Wall MA, Coleman DE, Lee E, Iniguez-Lluhi JA, Posner BA, Gilman AG, Sprang SR: The structure of the $\mathrm{G}$ protein heterotrimer $\mathrm{Gi}$ alpha 1 beta 1 gamma 2. Cell 1995, 83:1047-1058.

11. Garcia-Higuera I, Gaitatzes C, Smith TF, Neer EJ: Folding a WD repeat propeller. Role of highly conserved aspartic acid residues in the $G$ protein beta subunit and Sec13. J Biol Chem 1998, 273:9041-9049. 
12. Murzin AG: Structural principles for the propeller assembly of betasheets: the preference for seven-fold symmetry. Proteins 1992, 14:191-201.

13. Sondek J, Siderovski DP: Ggamma-like (GGL) domains: new frontiers in Gprotein signaling and beta-propeller scaffolding. Biochem Pharmacol 2001, 61:1329-1337.

14. Schwindinger WF, Robishaw JD: Heterotrimeric G-protein betagammadimers in growth and differentiation. Oncogene 2001, 20:1653-1660.

15. Tuteja N: Signaling through G protein coupled receptors. Plant Signal Behav 2009, 4:942-947.

16. Lambright DG, Sondek J, Bohm A, Skiba NP, Hamm HE, Sigler PB: The 2.0 A crystal structure of a heterotrimeric $G$ protein. Nature 1996, 379:311-319.

17. Nishimura A, Kitano K, Takasaki J, Taniguchi M, Mizuno N, Tago K, Hakoshima T, Itoh H: Structural basis for the specific inhibition of heterotrimeric Gq protein by a small molecule. Proc Natl Acad Sci USA 2010, 107:13666-13671.

18. Gaudet R, Bohm A, Sigler PB: Crystal structure at 2.4 angstroms resolution of the complex of transducin betagamma and its regulator, phosducin. Cell 1996, 87:577-588.

19. Gaudet R, Savage JR, McLaughlin JN, Willardson BM, Sigler PB: A molecular mechanism for the phosphorylation-dependent regulation of heterotrimeric G proteins by phosducin. Mol Cell 1999, 3:649-660.

20. Loew A, Ho YK, Blundell T, Bax B: Phosducin induces a structural change in transducin beta gamma. Structure 1998, 6:1007-1019.

21. Lodowski DT, Pitcher JA, Capel WD, Lefkowitz RJ, Tesmer JJ: Keeping G proteins at bay: a complex between $\mathrm{G}$ protein-coupled receptor kinase 2 and Gbetagamma. Science 2003, 300:1256-1262.

22. Tesmer JJ, Tesmer VM, Lodowski DT, Steinhagen H, Huber J: Structure of human $\mathrm{G}$ protein-coupled receptor kinase 2 in complex with the kinase inhibitor balanol. J Med Chem 2010, 53:1867-1870.

23. Tesmer VM, Kawano T, Shankaranarayanan A, Kozasa T, Tesmer JJ: Snapshot of activated $\mathrm{G}$ proteins at the membrane: the Galphaq-GRK2Gbetagamma complex. Science 2005, 310:1686-1690.

24. Cheever ML, Snyder JT, Gershburg S, Siderovski DP, Harden TK, Sondek J: Crystal structure of the multifunctional Gbeta5-RGS9 complex. Nat Struct Mol Biol 2008, 15:155-162.

25. Slep KC, Kercher MA, He W, Cowan CW, Wensel TG, Sigler PB: Structural determinants for regulation of phosphodiesterase by a $\mathrm{G}$ protein at 2.0 A. Nature 2001, 409:1071-1077.

26. Johnston CA, Kimple AJ, Giguere PM, Siderovski DP: Structure of the parathyroid hormone receptor $\mathrm{C}$ terminus bound to the $\mathrm{G}$-protein dimer Gbeta1gamma2. Structure 2008, 16:1086-1094.

27. Chen S, Dell EJ, Lin F, Sai J, Hamm HE: RACK1 regulates specific functions of Gbetagamma. J Biol Chem 2004, 279:17861-17868

28. Chen $S$, Lin F, Hamm HE: RACK1 binds to a signal transfer region of $G$ betagamma and inhibits phospholipase $\mathrm{C}$ beta2 activation. J Biol Chem 2005, 280:33445-33452.

29. Thornton C, Tang KC, Phamluong K, Luong K, Vagts A, Nikanjam D, Yaka R, Ron D: Spatial and temporal regulation of RACK1 function and Nmethyl-D-aspartate receptor activity through WD40 motif-mediated dimerization. J Biol Chem 2004, 279:31357-31364.

30. Vinas-Castells R, Beltran M, Valls G, Gomez I, Garcia JM, Montserrat-Sentis B, Baulida J, Bonilla F, de Herreros AG, Diaz VM: The hypoxia-controlled FBXL14 ubiquitin ligase targets SNAIL1 for proteasome degradation. J Biol Chem 2010, 285:3794-3805

31. Xia Y, Padre RC, De Mendoza TH, Bottero V, Tergaonkar VB, Verma IM: Phosphorylation of p53 by lkappaB kinase 2 promotes its degradation by beta-TrCP. Proc Natl Acad Sci USA 2009, 106:2629-2634.

32. Seo E, Kim H, Kim R, Yun S, Kim M, Han JK, Costantini F, Jho EH: Multiple isoforms of beta-TrCP display differential activities in the regulation of Wnt signaling. Cell Signal 2009, 21:43-51.

33. Kimbrel EA, Kung AL: The F-box protein beta- $\operatorname{TrCp} 1 /$ Fbw1a interacts with p300 to enhance beta-catenin transcriptional activity. J Biol Chem 2009, 284:13033-13044.

34. Ohsaki K, Oishi K, Kozono Y, Nakayama K, Nakayama Kl, Ishida N: The role of \{beta\}-TrCP1 and \{beta\}-TrCP2 in circadian rhythm generation by mediating degradation of clock protein PER2. J Biochem 2008 144:609-618.

35. Dentice M, Bandyopadhyay A, Gereben B, Callebaut I, Christoffolete MA, Kim BW, Nissim S, Mornon JP, Zavacki AM, Zeold A, et al: The Hedgehoginducible ubiquitin ligase subunit WSB-1 modulates thyroid hormone activation and PTHrP secretion in the developing growth plate. Nat Cell Biol 2005, 7:698-705.

36. Choi DW, Seo YM, Kim EA, Sung KS, Ahn JW, Park SJ, Lee SR, Choi CY: Ubiquitination and degradation of homeodomain-interacting protein kinase 2 by WD40 repeat/SOCS box protein WSB-1. J Biol Chem 2008, 283:4682-4689

37. Chen QR, Bilke S, Wei JS, Greer BT, Steinberg SM, Westermann F, Schwab M, Khan J: Increased WSB1 copy number correlates with its over-expression which associates with increased survival in neuroblastoma. Genes Chromosomes Cancer 2006, 45:856-862.

38. Tsai TC, Lee YL, Hsiao WC, Tsao YP, Chen SL: NRIP, a novel nuclear receptor interaction protein, enhances the transcriptional activity of nuclear receptors. J Biol Chem 2005, 280:20000-20009.

39. Chen PH, Tsao YP, Wang CC, Chen SL: Nuclear receptor interaction protein, a coactivator of androgen receptors (AR), is regulated by AR and $\mathrm{Sp} 1$ to feed forward and activate its own gene expression through AR protein stability. Nucleic Acids Res 2008, 36:51-66.

40. Chang SW, Tsao YP, Lin CY, Chen SL: NRIP, a Novel Calmodulin Binding Protein, Activates Calcineurin To Dephosphorylate Human Papillomavirus E2 Protein. J Virol 2011, 85:6750-6763.

41. Guillemot F, Billault A, Auffray C: Physical linkage of a guanine nucleotidebinding protein-related gene to the chicken major histocompatibility complex. Proc Natl Acad Sci USA 1989, 86:4594-4598.

42. Ron D, Chen CH, Caldwell J, Jamieson L, Orr E, Mochly-Rosen D: Cloning of an intracellular receptor for protein kinase $\mathrm{C}$ : a homolog of the beta subunit of G proteins. Proc Natl Acad Sci USA 1994, 91:839-843

43. Ron D, Luo J, Mochly-Rosen D: C2 region-derived peptides inhibit translocation and function of beta protein kinase C in vivo. J Biol Chem 1995, 270:24180-24187.

44. Ron D, Mochly-Rosen D: An autoregulatory region in protein kinase $C$ : the pseudoanchoring site. Proc Natl Acad Sci USA 1995, 92:492-496.

45. Stebbins EG, Mochly-Rosen D: Binding specificity for RACK1 resides in the V5 region of beta II protein kinase C. J Biol Chem 2001, 276:29644-29650.

46. McCahill A, Warwicker J, Bolger GB, Houslay MD, Yarwood SJ: The RACK1 scaffold protein: a dynamic cog in cell response mechanisms. Mol Pharmacol 2002, 62:1261-1273.

47. Sklan EH, Podoly E, Soreq H: RACK1 has the nerve to act: structure meets function in the nervous system. Prog Neurobiol 2006, 78:117-134.

48. Chang BY, Harte RA, Cartwright CA: RACK1: a novel substrate for the Src protein-tyrosine kinase. Oncogene 2002, 21:7619-7629.

49. Yaka R, Thornton C, Vagts AJ, Phamluong K, Bonci A, Ron D: NMDA receptor function is regulated by the inhibitory scaffolding protein, RACK1. Proc Natl Acad Sci USA 2002, 99:5710-5715.

50. Koehler JA, Moran MF: RACK1, a protein kinase $C$ scaffolding protein, interacts with the PH domain of p120GAP. Biochem Biophys Res Commun 2001, 283:888-895

51. Rodriguez MM, Ron D, Touhara $\mathrm{K}$, Chen CH, Mochly-Rosen D: RACK1, a protein kinase $\mathrm{C}$ anchoring protein, coordinates the binding of activated protein kinase $\mathrm{C}$ and select pleckstrin homology domains in vitro. Biochemistry 1999, 38:13787-13794.

52. Liedtke CM, Raghuram V, Yun CC, Wang X: Role of a PDZ1 domain of NHERF1 in the binding of airway epithelial RACK1 to NHERF1. Am J Physiol Cell Physiol 2004, 286:C1037-1044.

53. Dell EJ, Connor J, Chen S, Stebbins EG, Skiba NP, Mochly-Rosen D, Hamm HE: The betagamma subunit of heterotrimeric $G$ proteins interacts with RACK1 and two other WD repeat proteins. J Biol Chem 2002, 277:49888-49895

54. Liu YV, Semenza GL: RACK1 vs. HSP90: competition for HIF-1 alpha degradation vs. stabilization. Cell Cycle 2007, 6:656-659.

55. Wang J, Carnicella S, Phamluong K, Jeanblanc J, Ronesi JA, Chaudhri N, Janak PH, Lovinger DM, Ron D: Ethanol induces long-term facilitation of NR2B-NMDA receptor activity in the dorsal striatum: implications for alcohol drinking behavior. J Neurosci 2007, 27:3593-3602.

56. Yaka R, He DY, Phamluong K, Ron D: Pituitary adenylate cyclase-activating polypeptide (PACAP(1-38)) enhances N-methyl-D-aspartate receptor function and brain-derived neurotrophic factor expression via RACK1. J Biol Chem 2003, 278:9630-9638.

57. Yaka R, Phamluong K, Ron D: Scaffolding of Fyn kinase to the NMDA receptor determines brain region sensitivity to ethanol. J Neurosci 2003, 23:3623-3632. 
58. Kiely PA, Baillie GS, Lynch MJ, Houslay MD, O'Connor R: Tyrosine 302 in RACK1 is essential for insulin-like growth factor-l-mediated competitive binding of PP2A and beta1 integrin and for tumor cell proliferation and migration. J Biol Chem 2008, 283:22952-22961.

59. Kiely PA, O'Gorman D, Luong K, Ron D, O'Connor R: Insulin-like growth factor I controls a mutually exclusive association of RACK1 with protein phosphatase $2 \mathrm{~A}$ and beta1 integrin to promote cell migration. $\mathrm{Mol} \mathrm{Cell}$ Biol 2006, 26:4041-4051.

60. Ron D, Jiang Z, Yao L, Vagts A, Diamond I, Gordon A: Coordinated movement of RACK1 with activated betallPKC. J Biol Chem 1999, 274:27039-27046.

61. Mamidipudi V, Chang BY, Harte RA, Lee KC, Cartwright CA: RACK1 inhibits the serum- and anchorage-independent growth of v-Src transformed cells. FEBS Lett 2004, 567:321-326.

62. Mamidipudi V, Zhang J, Lee KC, Cartwright CA: RACK1 regulates G1/S progression by suppressing Src kinase activity. Mol Cell Biol 2004, 24:6788-6798.

63. Del Vecchio I, Zuccotti A, Pisano F, Canneva F, Lenzken SC, Rousset F, Corsini E, Govoni S, Racchi M: Functional mapping of the promoter region of the GNB2L1 human gene coding for RACK1 scaffold protein. Gene 2009, 430:17-29.

64. Wang S, Chen JZ, Zhang Z, Gu S, Ji C, Tang R, Ying K, Xie Y, Mao Y: Cloning, expression and genomic structure of a novel human GNB2L1 gene, which encodes a receptor of activated protein kinase C (RACK). Mol Biol Rep 2003, 30:53-60.

65. Glessner JT, Wang K, Sleiman PM, Zhang H, Kim CE, Flory JH, Bradfield JP, Imielinski M, Frackelton EC, Qiu H, et al: Duplication of the SLIT3 locus on 5q35.1 predisposes to major depressive disorder. PLoS One 2010, 5: e15463.

66. Rivera H, Vasquez-Velasquez Al: $5 q 35$ duplication and Hunter-McAlpine syndrome: missing the link. Am J Med Genet A 2010, 152A:802-803, author reply 804 .

67. Rauch A, Beese M, Mayatepek E, Dorr HG, Wenzel D, Reis A, Trautmann U: A novel $5 q 35.3$ subtelomeric deletion syndrome. Am J Med Genet A 2003, 121A:1-8.

68. Laurin N, Brown JP, Lemainque A, Duchesne A, Huot D, Lacourciere $Y$, Drapeau G, Verreault J, Raymond V, Morissette J: Paget disease of bone: mapping of two loci at 5q35-qter and 5q31. Am J Hum Genet 2001, 69:528-543.

69. Choi DS, Young H, McMahon T, Wang D, Messing RO: The mouse RACK1 gene is regulated by nuclear factor-kappa $B$ and contributes to cell survival. Mol Pharmacol 2003, 64:1541-1548.

70. Chou YC, Chou CC, Chen YK, Tsai S, Hsieh FM, Liu HJ, Hseu TH: Structure and genomic organization of porcine RACK1 gene. Biochim Biophys Acta 1999, 1489:315-322.

71. Ashique AM, Kharazia V, Yaka R, Phamluong K, Peterson AS, Ron D: Localization of the scaffolding protein RACK1 in the developing and adult mouse brain. Brain Res 2006, 1069:31-38.

72. Battaini $F$, Pascale $A$ : Protein kinase $C$ signal transduction regulation in physiological and pathological aging. Ann N Y Acad Sci 2005, 1057:177-192.

73. Battaini F, Pascale A, Lucchi L, Pasinetti GM, Govoni S: Protein kinase C anchoring deficit in postmortem brains of Alzheimer's disease patients. Exp Neurol 1999, 159:559-564.

74. Peyrl A, Weitzdoerfer R, Gulesserian T, Fountoulakis M, Lubec G: Aberrant expression of signaling-related proteins 14-3-3 gamma and RACK1 in fetal Down syndrome brain (trisomy 21). Electrophoresis 2002, 23:152-157.

75. Chang BY, Conroy KB, Machleder EM, Cartwright CA: RACK1, a receptor for activated $C$ kinase and a homolog of the beta subunit of $G$ proteins, inhibits activity of src tyrosine kinases and growth of NIH 3 T3 cells. Mol Cell Biol 1998, 18:3245-3256.

76. Hermanto U, Zong CS, Li W, Wang LH: RACK1, an insulin-like growth factor I (IGF-I) receptor-interacting protein, modulates IGF-I-dependent integrin signaling and promotes cell spreading and contact with extracellular matrix. Mol Cell Biol 2002, 22:2345-2365.

77. Kiely PA, Sant A, O'Connor R: RACK1 is an insulin-like growth factor 1 (IGF-1) receptor-interacting protein that can regulate IGF-1-mediated Akt activation and protection from cell death. J Biol Chem 2002, 277:22581-22589.
78. Stirnimann CU, Petsalaki E, Russell RB, Muller CW: WD40 proteins propel cellular networks. Trends Biochem Sci 2010, 35:565-574.

79. Coyle SM, Gilbert W, Doudna JA: Direct link between RACK1 function and localization at the ribosome in vivo. Mol Cell Biol 2009, 29:1626-1634

80. Rabl J, Leibundgut M, Ataide SF, Haag A, Ban N: Crystal structure of the eukaryotic $40 \mathrm{~S}$ ribosomal subunit in complex with initiation factor 1. Science 2011, 331:730-736.

81. Ullah H, Scappini EL, Moon AF, Williams LV, Armstrong DL, Pedersen LC: Structure of a signal transduction regulator, RACK1, from Arabidopsis thaliana. Protein Sci 2008, 17:1771-1780.

82. Yatime L, Hein KL, Nilsson J, Nissen P: Structure of the RACK1 Dimer from Saccharomyces cerevisiae. J Mol Biol 2011, 411:486-498.

83. Ben-Shem A, Jenner L, Yusupova G, Yusupov M: Crystal structure of the eukaryotic ribosome. Science 2010, 330:1203-1209.

84. Sengupta J, Nilsson J, Gursky R, Spahn CM, Nissen P, Frank J: Identification of the versatile scaffold protein RACK1 on the eukaryotic ribosome by cryo-EM. Nat Struct Mol Biol 2004, 11:957-962.

85. Chandramouli P, Topf M, Menetret JF, Eswar N, Cannone JJ, Gutell RR, Sali A, Akey CW: Structure of the mammalian $80 \mathrm{~S}$ ribosome at $8.7 \mathrm{~A}$ resolution. Structure 2008, 16:535-548

86. Angenstein F, Evans AM, Settlage RE, Moran ST, Ling SC, Klintsova AY, Shabanowitz J, Hunt DF, Greenough WT: A receptor for activated C kinase is part of messenger ribonucleoprotein complexes associated with polyA-mRNAs in neurons. J Neurosci 2002, 22:8827-8837.

87. Becker T, Bhushan S, Jarasch A, Armache JP, Funes S, Jossinet F, Gumbart J, Mielke T, Berninghausen $O$, Schulten $K$, et al: Structure of monomeric yeast and mammalian Sec61 complexes interacting with the translating ribosome. Science 2009, 326:1369-1373.

88. Taylor DJ, Devkota B, Huang AD, Topf M, Narayanan E, Sali A, Harvey SC, Frank J: Comprehensive molecular structure of the eukaryotic ribosome. Structure 2009, 17:1591-1604.

89. Armache JP, Jarasch A, Anger AM, Villa E, Becker T, Bhushan S, Jossinet F, Habeck M, Dindar G, Franckenberg S, et al: Localization of eukaryotespecific ribosomal proteins in a 5.5-A cryo-EM map of the $80 \mathrm{~S}$ eukaryotic ribosome. Proc Natl Acad Sci USA 2010, 107:19754-19759.

90. Armache JP, Jarasch A, Anger AM, Villa E, Becker T, Bhushan S, Jossinet F, Habeck M, Dindar G, Franckenberg S, et al: Cryo-EM structure and rRNA model of a translating eukaryotic $80 \mathrm{~S}$ ribosome at 5.5-A resolution. Proc Natl Acad Sci USA 2010, 107:19748-19753.

91. Ceci M, Gaviraghi C, Gorrini C, Sala LA, Offenhauser N, Marchisio PC, Biffo S: Release of elF6 (p27BBP) from the 60S subunit allows 805 ribosome assembly. Nature 2003, 426:579-584.

92. Grosso S, Volta V, Sala LA, Vietri M, Marchisio PC, Ron D, Biffo S: PKCbetall modulates translation independently from mTOR and through RACK1. Biochem J 2008, 415:77-85.

93. Grosso S, Volta V, Vietri M, Gorrini C, Marchisio PC, Biffo S: Eukaryotic ribosomes host PKC activity. Biochem Biophys Res Commun 2008, 376:65-69

94. Banci L, Cavallaro G, Kheifets V, Mochly-Rosen D: Molecular dynamics characterization of the C2 domain of protein kinase Cbeta. J Biol Chem 2002, 277:12988-12997.

95. Ron D, Mochly-Rosen D: Agonists and antagonists of protein kinase C function, derived from its binding proteins. J Biol Chem 1994, 269:21395-21398.

96. Brandon NJ, Jovanovic JN, Smart TG, Moss SJ: Receptor for activated C kinase-1 facilitates protein kinase $\mathrm{C}$-dependent phosphorylation and functional modulation of $\mathrm{GABA}(\mathrm{A})$ receptors with the activation of $\mathrm{G}$ protein-coupled receptors. J Neurosci 2002, 22:6353-6361.

97. Schechtman D, Mochly-Rosen D: Adaptor proteins in protein kinase Cmediated signal transduction. Oncogene 2001, 20:6339-6347.

98. Haberman Y, Alon LT, Eliyahu E, Shalgi R: Receptor for activated C kinase (RACK) and protein kinase C (PKC) in egg activation. Theriogenology 2011, 75:80-89.

99. Pass JM, Gao J, Jones WK, Wead WB, Wu X, Zhang J, Baines CP, Bolli R, Zheng YT, Joshua IG, Ping P: Enhanced PKC beta II translocation and PKC beta II-RACK1 interactions in PKC epsilon-induced heart failure: a role for RACK1. Am J Physiol Heart Circ Physiol 2001, 281:H2500-2510.

100. Pass JM, Zheng Y, Wead WB, Zhang J, Li RC, Bolli R, Ping P: PKCepsilon activation induces dichotomous cardiac phenotypes and modulates 
PKCepsilon-RACK interactions and RACK expression. Am J Physiol Heart Circ Physiol 2001, 280:H946-955.

101. Lopez-Bergami P, Habelhah H, Bhoumik A, Zhang W, Wang LH, Ronai Z: RACK1 mediates activation of JNK by protein kinase $C$ [corrected]. Mol Cell 2005, 19:309-320.

102. Massip L, Garand C, Labbe A, Perreault E, Turaga RV, Bohr VA, Lebel M: Depletion of WRN protein causes RACK1 to activate several protein kinase C isoforms. Oncogene 2010, 29:1486-1497.

103. Robles MS, Boyault C, Knutti D, Padmanabhan K, Weitz CJ: Identification of RACK1 and protein kinase Calpha as integral components of the mammalian circadian clock. Science 2010, 327:463-466.

104. Dehghani $\mathrm{H}$, Hahnel AC: Expression profile of protein kinase $\mathrm{C}$ isozymes in preimplantation mouse development. Reproduction 2005, 130:441-451.

105. Bird RJ, Baillie GS, Yarwood SJ: Interaction with receptor for activated Ckinase 1 (RACK1) sensitizes the phosphodiesterase PDE4D5 towards hydrolysis of CAMP and activation by protein kinase C. Biochem J 2010, 432:207-216

106. He DY, Neasta J, Ron D: Epigenetic regulation of BDNF expression via the scaffolding protein RACK1.J Biol Chem 2010, 285:19043-19050.

107. Yarwood SJ, Steele MR, Scotland G, Houslay MD, Bolger GB: The RACK1 signaling scaffold protein selectively interacts with the CAMP-specific phosphodiesterase PDE4D5 isoform. J Biol Chem 1999, 274:14909-14917.

108. Houslay MD, Adams DR: PDE4 CAMP phosphodiesterases: modular enzymes that orchestrate signalling cross-talk, desensitization and compartmentalization. Biochem J 2003, 370:1-18.

109. Bolger GB, Baillie GS, Li X, Lynch MJ, Herzyk P, Mohamed A, Mitchell LH, McCahill A, Hundsrucker C, Klussmann E, et al: Scanning peptide array analyses identify overlapping binding sites for the signalling scaffold proteins, beta-arrestin and RACK1, in CAMP-specific phosphodiesterase PDE4D5. Biochem J 2006, 398:23-36.

110. Bolger GB, McCahill A, Yarwood SJ, Steele MR, Warwicker J, Houslay MD: Delineation of RAID1, the RACK1 interaction domain located within the unique $\mathrm{N}$-terminal region of the CAMP-specific phosphodiesterase, PDE4D5. BMC Biochem 2002, 3:24

111. Serrels B, Sandilands E, Frame MC: Signaling of the direction-sensing FAK/ RACK1/PDE4D5 complex to the small GTPase Rap1. Small Gtpases 2011, 2:54-61.

112. Serrels B, Sandilands E, Serrels A, Baillie G, Houslay MD, Brunton VG, Canel M, Machesky LM, Anderson Kl, Frame MC: A complex between FAK, RACK1, and PDE4D5 controls spreading initiation and cancer cell polarity. Curr Biol 2010, 20:1086-1092.

113. Kiely PA, Leahy M, O'Gorman D, O'Connor R: RACK1-mediated integration of adhesion and insulin-like growth factor I (IGF-I) signaling and cell migration are defective in cells expressing an IGF-I receptor mutated at tyrosines 1250 and 1251. J Biol Chem 2005, 280:7624-7633.

114. Mamidipudi V, Dhillon NK, Parman T, Miller LD, Lee KC, Cartwright CA: RACK1 inhibits colonic cell growth by regulating Src activity at cell cycle checkpoints. Oncogene 2007, 26:2914-2924.

115. Swaminathan G, Cartwright CA: Rack1 promotes epithelial cell-cell adhesion by regulating E-cadherin endocytosis. Oncogene 2011.

116. Geijsen N, Spaargaren M, Raaijmakers JA, Lammers JW, Koenderman L, Coffer PJ: Association of RACK1 and PKCbeta with the common betachain of the IL-5/IL-3/GM-CSF receptor. Oncogene 1999, 18:5126-5130.

117. Usacheva A, Smith R, Minshall R, Baida G, Seng S, Croze E, Colamonici O: The WD motif-containing protein receptor for activated protein kinase $C$ (RACK1) is required for recruitment and activation of signal transducer and activator of transcription 1 through the type I interferon receptor. J Biol Chem 2001, 276:22948-22953.

118. Patterson RL, van Rossum DB, Barrow RK, Snyder SH: RACK1 binds to inositol 1,4,5-trisphosphate receptors and mediates $\mathrm{Ca} 2+$ release. Proc Natl Acad Sci USA 2004, 101:2328-2332.

119. Reiner CL, McCullar JS, Kow RL, Le JH, Goodlett DR, Nathanson NM: RACK1 associates with muscarinic receptors and regulates $\mathrm{M}(2)$ receptor trafficking. PLoS One 2010, 5:e13517.

120. Xu Y, Wang N, Ling F, Li P, Gao Y: Receptor for activated C-kinase 1, a novel binding partner of adiponectin receptor 1. Biochem Biophys Res Commun 2009, 378:95-98.

121. Rigas AC, Ozanne DM, Neal DE, Robson CN: The scaffolding protein RACK1 interacts with androgen receptor and promotes cross-talk through a protein kinase C signaling pathway. J Biol Chem 2003, 278:46087-46093.
122. Zhang W, Zong CS, Hermanto U, Lopez-Bergami P, Ronai Z, Wang LH: RACK1 recruits STAT3 specifically to insulin and insulin-like growth factor 1 receptors for activation, which is important for regulating anchorage-independent growth. Mol Cell Biol 2006, 26:413-424.

123. Liliental J, Chang DD: Rack1, a receptor for activated protein kinase C, interacts with integrin beta subunit. J Biol Chem 1998, 273:2379-2383.

124. Kiely PA, Baillie GS, Barrett R, Buckley DA, Adams DR, Houslay MD, $\mathrm{O}^{\prime}$ Connor R: Phosphorylation of RACK1 on tyrosine 52 by c-Abl is required for insulin-like growth factor I-mediated regulation of focal adhesion kinase. J Biol Chem 2009, 284:20263-20274.

125. De Toni-Costes F, Despeaux M, Bertrand J, Bourogaa E, Ysebaert L, Payrastre B, Racaud-Sultan C: A New alpha5beta1 integrin-dependent survival pathway through GSK3beta activation in leukemic cells. PLOS One 2010, 5:e9807.

126. Vomastek T, Iwanicki MP, Schaeffer HJ, Tarcsafalvi A, Parsons JT, Weber MJ: RACK1 targets the extracellular signal-regulated kinase/mitogenactivated protein kinase pathway to link integrin engagement with focal adhesion disassembly and cell motility. Mol Cell Biol 2007, 27:8296-8305.

127. Besson A, Wilson TL, Yong WW: The anchoring protein RACK1 links protein kinase Cepsilon to integrin beta chains. Requirements for adhesion and motility. J Biol Chem 2002, 277:22073-22084.

128. Buensuceso CS, Woodside D, Huff JL, Plopper GE, OToole TE: The WD protein Rack1 mediates protein kinase $\mathrm{C}$ and integrin-dependent cel migration. J Cell Sci 2001, 114:1691-1698.

129. Lee HS, Millward-Sadler SJ, Wright MO, Nuki G, Al-Jamal R, Salter DM: Activation of Integrin-RACK1/PKCalpha signalling in human articular chondrocyte mechanotransduction. Osteoarthritis Cartilage 2002, 10:890-897.

130. Brandon NJ, Uren JM, Kittler JT, Wang H, Olsen R, Parker PJ, Moss SJ: Subunit-specific association of protein kinase $C$ and the receptor for activated C kinase with GABA type A receptors. J Neurosci 1999, 19:9228-9234.

131. Feng J, Cai X, Zhao J, Yan Z: Serotonin receptors modulate GABA(A) receptor channels through activation of anchored protein kinase $C$ in prefrontal cortical neurons. J Neurosci 2001, 21:6502-6511.

132. Isacson CK, Lu Q, Karas RH, Cox DH: RACK1 is a BKCa channel binding protein. Am J Physiol Cell Physiol 2007, 292:C1459-1466.

133. Kraus S, Gioeli D, Vomastek T, Gordon V, Weber MJ: Receptor for activated C kinase 1 (RACK1) and Src regulate the tyrosine phosphorylation and function of the androgen receptor. Cancer Res 2006, 66:11047-11054

134. Birikh KR, Sklan EH, Shoham S, Soreq H: Interaction of "readthrough" acetylcholinesterase with RACK1 and PKCbeta II correlates with intensified fear-induced conflict behavior. Proc Natl Acad Sci USA 2003, 100:283-288

135. Farchi N, Ofek K, Podoly E, Dong H, Xiang YY, Diamant S, Livnah O, Li J, Hochner B, Lu WY, Soreq H: Peripheral site acetylcholinesterase blockade induces RACK1-associated neuronal remodeling. Neurodegener Dis 2007, 4:171-184

136. Arimoto K, Fukuda H, Imajoh-Ohmi S, Saito H, Takekawa M: Formation of stress granules inhibits apoptosis by suppressing stress-responsive MAPK pathways. Nat Cell Biol 2008, 10:1324-1332.

137. Ohn T, Kedersha N, Hickman T, Tisdale S, Anderson P: A functional RNAi screen links O-GICNAc modification of ribosomal proteins to stress granule and processing body assembly. Nat Cell Biol 2008, 10:1224-1231.

138. Chang BY, Chiang M, Cartwright CA: The interaction of Src and RACK1 is enhanced by activation of protein kinase $C$ and tyrosine phosphorylation of RACK1. J Biol Chem 2001, 276:20346-20356.

139. Mamidipudi V, Miller LD, Mochly-Rosen D, Cartwright CA: Peptide modulators of Src activity in G1 regulate entry into S phase and proliferation of NIH 3T3 cells. Biochem Biophys Res Commun 2007, 352:423-430.

140. Liu YV, Hubbi ME, Pan F, McDonald KR, Mansharamani M, Cole RN, Liu JO, Semenza GL: Calcineurin promotes hypoxia-inducible factor 1alpha expression by dephosphorylating RACK1 and blocking RACK1 dimerization. J Biol Chem 2007, 282:37064-37073.

141. He DY, Vagts AJ, Yaka R, Ron D: Ethanol induces gene expression via nuclear compartmentalization of receptor for activated C kinase 1 . Mol Pharmacol 2002, 62:272-280.

142. Ron D, Vagts AJ, Dohrman DP, Yaka R, Jiang Z, Yao L, Crabbe J, Grisel JE, Diamond I: Uncoupling of betallPKC from its targeting protein RACK1 in 
response to ethanol in cultured cells and mouse brain. FASEB J 2000, 14:2303-2314.

143. McGough NN, He DY, Logrip ML, Jeanblanc J, Phamluong K, Luong K, Kharazia V, Janak PH, Ron D: RACK1 and brain-derived neurotrophic factor: a homeostatic pathway that regulates alcohol addiction. J Neurosci 2004, 24:10542-10552.

144. Nery FC, Passos DO, Garcia VS, Kobarg J: Ki-1/57 interacts with RACK1 and is a substrate for the phosphorylation by phorbol 12-myristate 13acetate-activated protein kinase C. J Biol Chem 2004, 279:11444-11455.

145. Liu YV, Baek JH, Zhang H, Diez R, Cole RN, Semenza GL: RACK1 competes with HSP90 for binding to HIF-1alpha and is required for O(2)independent and HSP90 inhibitor-induced degradation of HIF-1alpha. Mol Cell 2007, 25:207-217.

146. Nilsson J, Sengupta J, Frank J, Nissen P: Regulation of eukaryotic translation by the RACK1 protein: a platform for signalling molecules on the ribosome. EMBO Rep 2004, 5:1137-1141.

147. Link AJ, Eng J, Schieltz DM, Carmack E, Mize GJ, Morris DR, Garvik BM, Yates JR: Direct analysis of protein complexes using mass spectrometry. Nat Biotechnol 1999, 17:676-682.

148. Gerbasi VR, Weaver CM, Hill S, Friedman DB, Link AJ: Yeast Asc1p and mammalian RACK1 are functionally orthologous core $40 \mathrm{~S}$ ribosomal proteins that repress gene expression. Mol Cell Biol 2004, 24:8276-8287.

149. Nunez A, Franco A, Madrid M, Soto T, Vicente J, Gacto M, Cansado J: Role for RACK1 orthologue Cpc2 in the modulation of stress response in fission yeast. Mol Biol Cell 2009, 20:3996-4009.

150. Nunez A, Franco A, Soto T, Vicente J, Gacto M, Cansado J: Fission yeast receptor of activated $\mathrm{C}$ kinase (RACK1) ortholog $\mathrm{Cpc} 2$ regulates mitotic commitment through Wee1 kinase. J Biol Chem 2010, 285:41366-41373.

151. Shor B, Calaycay J, Rushbrook J, McLeod M: Cpc2/RACK1 is a ribosomeassociated protein that promotes efficient translation in Schizosaccharomyces pombe. J Biol Chem 2003, 278:49119-49128.

152. Manuell AL, Yamaguchi K, Haynes PA, Milligan RA, Mayfield SP: Composition and structure of the $80 \mathrm{~S}$ ribosome from the green alga Chlamydomonas reinhardtii: 80S ribosomes are conserved in plants and animals. J Mol Biol 2005, 351:266-279.

153. Chang IF, Szick-Miranda K, Pan S, Bailey-Serres J: Proteomic characterization of evolutionarily conserved and variable proteins of Arabidopsis cytosolic ribosomes. Plant Physiol 2005, 137:848-862.

154. Giavalisco P, Wilson D, Kreitler T, Lehrach H, Klose J, Gobom J, Fucini P: High heterogeneity within the ribosomal proteins of the Arabidopsis thaliana 80 S ribosome. Plant Mol Biol 2005, 57:577-591.

155. Guo J, Jin Z, Yang X, Li JF, Chen JG: Eukaryotic Initiation Factor 6, an evolutionarily conserved regulator of ribosome biogenesis and protein translation. Plant Signal Behav 2011, 6:766-771.

156. Guo J, Wang S, Valerius O, Hall H, Zeng Q, Li JF, Weston DJ, Ellis BE, Chen JG: Involvement of Arabidopsis RACK1 in protein translation and its regulation by abscisic acid. Plant Physiol 2011, 155:370-383.

157. Jannot G, Bajan S, Giguere NJ, Bouasker S, Banville IH, Piquet S, Hutvagner G, Simard MJ: The ribosomal protein RACK1 is required for microRNA function in both C. elegans and humans. EMBO Rep 2011, 12:581-586.

158. Kuroha K, Akamatsu M, Dimitrova L, Ito T, Kato Y, Shirahige K, Inada T: Receptor for activated C kinase 1 stimulates nascent polypeptidedependent translation arrest. EMBO Rep 2010, 11:956-961.

159. Baum S, Bittins M, Frey S, Seedorf M: Asc1p, a WD40-domain containing adaptor protein, is required for the interaction of the RNA-binding protein Scp160p with polysomes. Biochem J 2004, 380:823-830.

160. Li S, Esterberg R, Lachance V, Ren D, Radde-Gallwitz K, Chi F, Parent JL, Fritz A, Chen P: Rack1 is required for Vangl2 membrane localization and planar cell polarity signaling while attenuating canonical Wnt activity. Proc Natl Acad Sci USA 2011, 108:2264-2269.

161. Wehner P, Shnitsar I, Urlaub H, Borchers A: RACK1 is a novel interaction partner of PTK7 that is required for neural tube closure. Development 2011, 138:1321-1327.

162. Chen JG, Ullah H, Temple B, Liang J, Guo J, Alonso JM, Ecker JR, Jones AM: RACK1 mediates multiple hormone responsiveness and developmental processes in Arabidopsis. J Exp Bot 2006, 57:2697-2708.

163. Guo J, Chen JG: RACK1 genes regulate plant development with unequal genetic redundancy in Arabidopsis. BMC Plant Biol 2008, 8:108.
164. Kadrmas JL, Smith MA, Pronovost SM, Beckerle MC: Characterization of RACK1 function in Drosophila development. Dev Dyn 2007, 236:2207-2215.

165. Hoffmann B, Wanke C, Lapaglia SK, Braus GH: c-Jun and RACK1 homologues regulate a control point for sexual development in Aspergillus nidulans. Mol Microbiol 2000, 37:28-41.

166. McLeod M, Shor B, Caporaso A, Wang W, Chen H, Hu L: Cpc2, a fission yeast homologue of mammalian RACK1 protein, interacts with Ran1 (Pat1) kinase To regulate cell cycle progression and meiotic development. Mol Cell Biol 2000, 20:4016-4027.

167. Rothberg KG, Burdette DL, Pfannstiel J, Jetton N, Singh R, Ruben L: The RACK1 homologue from Trypanosoma brucei is required for the onset and progression of cytokinesis. J Biol Chem 2006, 281:9781-9790.

168. Cox EA, Bennin D, Doan AT, OToole T, Huttenlocher A: RACK1 regulates integrin-mediated adhesion, protrusion, and chemotactic cell migration via its Src-binding site. Mol Biol Cell 2003, 14:658-669.

169. Onishi I, Lin PJ, Diering GH, Williams WP, Numata M: RACK1 associates with NHE5 in focal adhesions and positively regulates the transporter activity. Cell Signal 2007, 19:194-203.

170. Buensuceso CS, Obergfell A, Soriani A, Eto K, Kiosses WB, Arias-Salgado EG, Kawakami T, Shattil SJ: Regulation of outside-in signaling in platelets by integrin-associated protein kinase C beta. J Biol Chem 2005, 280:644-653.

171. Lo SH: Focal adhesions: what's new inside. Dev Biol 2006, 294:280-291.

172. Romer LH, Birukov KG, Garcia JG: Focal adhesions: paradigm for a signaling nexus. Circ Res 2006, 98:606-616.

173. Petit V, Thiery JP: Focal adhesions: structure and dynamics. Biol Cell 2000 92:477-494.

174. Martin GM: Fak and focal adhesions. Jpn J Cancer Res 1996, 87, inside front cover.

175. Burridge K, Chrzanowska-Wodnicka M: Focal adhesions, contractility, and signaling. Annu Rev Cell Dev Biol 1996, 12:463-518.

176. Guan JL: Integrin signaling through FAK in the regulation of mammary stem cells and breast cancer. IUBMB Life 2010, 62:268-276

177. Mitra SK, Schlaepfer DD: Integrin-regulated FAK-Src signaling in normal and cancer cells. Curr Opin Cell Biol 2006, 18:516-523.

178. Wang F, Yamauchi M, Muramatsu M, Osawa T, Tsuchida R, Shibuya M: RACK1 regulates VEGF/Flt1-mediated cell migration via activation of a PI3K/Akt pathway. J Biol Chem 2011, 286:9097-9106.

179. Nakashima A, Chen L, Thao NP, Fujiwara M, Wong HL, Kuwano M, Umemura K, Shirasu K, Kawasaki T, Shimamoto K: RACK1 functions in rice innate immunity by interacting with the Rac1 immune complex. Plant Cell 2008, 20:2265-2279.

180. Orlichenko L, Geyer R, Yanagisawa M, Khauv D, Radisky ES, Anastasiadis PZ, Radisky DC: The 19-amino acid insertion in the tumor-associated splice isoform Rac1b confers specific binding to p120 catenin. J Biol Chem 2010, 285:19153-19161.

181. Chen S, Lin F, Shin ME, Wang F, Shen L, Hamm HE: RACK1 regulates directional cell migration by acting on $\mathrm{G}$ betagamma at the interface with its effectors PLC beta and PI3K gamma. Mol Biol Cell 2008, 19:3909-3922.

182. Doan AT, Huttenlocher A: RACK1 regulates Src activity and modulates paxillin dynamics during cell migration. Exp Cell Res 2007, 313:2667-2679.

183. Miller LD, Lee KC, Mochly-Rosen D, Cartwright CA: RACK1 regulates Srcmediated Sam68 and p190RhoGAP signaling. Oncogene 2004, 23:5682-5686.

184. Mamidipudi V, Cartwright CA: A novel pro-apoptotic function of RACK1: suppression of Src activity in the intrinsic and Akt pathways. Oncogene 2009, 28:4421-4433.

185. Mourton T, Hellberg CB, Burden-Gulley SM, Hinman J, Rhee A, BradyKalnay SM: The PTPmu protein-tyrosine phosphatase binds and recruits the scaffolding protein RACK1 to cell-cell contacts. J Biol Chem 2001, 276:14896-14901

186. Qiu Y, Mao T, Zhang Y, Shao M, You J, Ding Q, Chen Y, Wu D, Xie D, Lin X, et al: A crucial role for RACK1 in the regulation of glucose-stimulated IRE1alpha activation in pancreatic beta cells. Sci Signal 2010, 3:ra7.

187. Ensslen SE, Brady-Kalnay SM: PTPmu signaling via PKCdelta is instructive for retinal ganglion cell guidance. Mol Cell Neurosci 2004, 25:558-571.

188. Hellberg CB, Burden-Gulley SM, Pietz GE, Brady-Kalnay SM: Expression of the receptor protein-tyrosine phosphatase, PTPmu, restores E-cadherin- 
dependent adhesion in human prostate carcinoma cells. J Biol Chem 2002, 277:11165-11173.

189. Rosdahl JA, Mourton TL, Brady-Kalnay SM: Protein kinase C delta (PKCdelta) is required for protein tyrosine phosphatase mu (PTPmu)dependent neurite outgrowth. Mol Cell Neurosci 2002, 19:292-306.

190. Zakrzewicz A, Hecker M, Marsh LM, Kwapiszewska G, Nejman B, Long L, Seeger W, Schermuly RT, Morrell NW, Morty RE, Eickelberg O: Receptor for activated C-kinase 1, a novel interaction partner of type II bone morphogenetic protein receptor, regulates smooth muscle cell proliferation in pulmonary arterial hypertension. Circulation 2007, 115:2957-2968.

191. Padanilam BJ: Induction and subcellular localization of protein kinase $C$ isozymes following renal ischemia. Kidney Int 2001, 59:1789-1797.

192. Calura E, Cagnin S, Raffaello A, Laveder P, Lanfranchi G, Romualdi C: Metaanalysis of expression signatures of muscle atrophy: gene interaction networks in early and late stages. BMC Genomics 2008, 9:630.

193. Mor I, Sklan EH, Podoly E, Pick M, Kirschner M, Yogev L, Bar-Sheshet Itach S, Schreiber L, Geyer B, Mor T, et al: Acetylcholinesterase-R increases germ cell apoptosis but enhances sperm motility. J Cell Mol Med 2008, 12:479-495.

194. Wang H, Friedman E: Increased association of brain protein kinase $\mathrm{C}$ with the receptor for activated C kinase-1 (RACK1) in bipolar affective disorder. Biol Psychiatry 2001, 50:364-370.

195. Pascale A, Fortino I, Govoni S, Trabucchi M, Wetsel WC, Battaini F: Functional impairment in protein kinase $C$ by RACK1 (receptor for activated $C$ kinase 1) deficiency in aged rat brain cortex. $J$ Neurochem 1996, 67:2471-2477.

196. Shimohama S, Kamiya S, Taniguchi T, Kimura J: Intracellular receptors for activated C-kinase in the postmortem human brain: no alteration in Alzheimer disease. Alzheimer Dis Assoc Disord 1998, 12:384-386.

197. Matsushima H, Shimohama S, Chachin M, Taniguchi T, Kimura J: Ca2 +-dependent and $\mathrm{Ca} 2+$-independent protein kinase $\mathrm{C}$ changes in the brain of patients with Alzheimer's disease. J Neurochem 1996, 67:317-323.

198. Liu W, Dou F, Feng J, Yan Z: RACK1 is involved in beta-amyloid impairment of muscarinic regulation of GABAergic transmission. Neurobiol Aging 2009.

199. Mourtada-Maarabouni M, Kirkham L, Farzaneh F, Williams GT: Functional expression cloning reveals a central role for the receptor for activated protein kinase C 1 (RACK1) in T cell apoptosis. J Leukoc Biol 2005, 78:503-514.

200. Baumann M, Gires O, Kolch W, Mischak H, Zeidler R, Pich D, Hammerschmidt W: The PKC targeting protein RACK1 interacts with the Epstein-Barr virus activator protein BZLF1. Eur J Biochem 2000, 267:3891-3901.

201. Daniels CC, Rovnak J, Quackenbush SL: Walleye dermal sarcoma virus Orf $B$ functions through receptor for activated $\mathrm{C}$ kinase (RACK1) and protein kinase C. Virology 2008, 375:550-560.

202. Kubota T, Yokosawa N, Yokota S, Fujii N: Association of mumps virus V protein with RACK1 results in dissociation of STAT-1 from the alpha interferon receptor complex. J Virol 2002, 76:12676-12682.

203. Al-Reefy S, Mokbel K: The role of RACK1 as an independent prognostic indicator in human breast cancer. Breast Cancer Res Treat 2010, 123:911, author reply 912

204. Al-Reefy S, Osman H, Jiang W, Mokbel K: Evidence for a pro-apoptotic function of RACK1 in human breast cancer. Oncogene 2010, 29:5651, author reply 5652.

205. Cao XX, Xu JD, Liu XL, Xu JW, Wang WJ, Li QQ, Chen Q, Xu ZD, Liu XP: RACK1: A superior independent predictor for poor clinical outcome in breast cancer. Int I Cancer 2010, 127:1172-1179.

206. Nagashio R, Sato Y, Matsumoto T, Kageyama T, Satoh Y, Shinichiro R, Masuda N, Goshima N, Jiang SX, Okayasu I: Expression of RACK1 is a novel biomarker in pulmonary adenocarcinomas. Lung Cancer 2010, 69:54-59.

207. Seidl P, Huettinger R, Knuechel R, Kunz-Schughart LA: Three-dimensional fibroblast-tumor cell interaction causes downregulation of RACK1 mRNA expression in breast cancer cells in vitro. Int J Cancer 2002, 102:129-136.

208. Zhang W, Cheng GZ, Gong J, Hermanto U, Zong CS, Chan J, Cheng JQ, Wang LH: RACK1 and CIS mediate the degradation of BimEL in cancer cells. J Biol Chem 2008, 283:16416-16426.

209. Bourd-Boittin K, Le Pabic H, Bonnier D, L'Helgoualc'h A, Theret N: RACK1, a new ADAM12 interacting protein. Contribution to liver fibrogenesis. J Biol Chem 2008, 283:26000-26009
210. Egidy G, Jule S, Bosse P, Bernex F, Geffrotin C, Vincent-Naulleau S, Horak V, Sastre-Garau X, Panthier JJ: Transcription analysis in the MeLiM swine model identifies RACK1 as a potential marker of malignancy for human melanocytic proliferation. Mol Cancer 2008, 7:34.

211. Lopez-Bergami P, Huang C, Goydos JS, Yip D, Bar-Eli M, Herlyn M, Smalley KS, Mahale A, Eroshkin A, Aaronson S, Ronai Z: Rewired ERK-JNK signaling pathways in melanoma. Cancer Cell 2007, 11:447-460.

212. Williams SR, Son DS, Terranova PF: Protein kinase $C$ delta is activated in mouse ovarian surface epithelial cancer cells by $2,3,7,8-$ tetrachlorodibenzo-p-dioxin (TCDD). Toxicology 2004, 195:1-17.

213. Boner W, Morgan IM: Novel cellular interacting partners of the human papillomavirus 16 transcription/replication factor E2. Virus Res 2002, 90:113-118.

214. Hennig EE, Butruk E, Ostrowski J: RACK1 protein interacts with Helicobacter pylori VacA cytotoxin: the yeast two-hybrid approach. Biochem Biophys Res Commun 2001, 289:103-110.

215. Berns H, Humar R, Hengerer B, Kiefer FN, Battegay EJ: RACK1 is upregulated in angiogenesis and human carcinomas. FASEB J 2000, 14:2549-2558.

216. Amir S, Golan M, Mabjeesh NJ: Targeted knockdown of SEPT9_v1 inhibits tumor growth and angiogenesis of human prostate cancer cells concomitant with disruption of hypoxia-inducible factor-1 pathway. Mol Cancer Res 2010, 8:643-652.

217. Amir S, Wang R, Simons JW, Mabjeesh NJ: SEPT9_v1 up-regulates hypoxiainducible factor 1 by preventing its RACK1-mediated degradation. J Biol Chem 2009, 284:11142-11151.

218. Huang CF, Fan JH, Chuang NN: Farnesyl pyrophosphate promotes and is essential for the binding of RACK1 with beta-tubulin. J Exp Zool A Comp Exp Biol 2003, 298:119-127.

219. Koob GF, Volkow ND: Neurocircuitry of addiction. Neuropsychopharmacology 2010, 35:217-238.

220. Escriba PV, Garcia-Sevilla JA: Parallel modulation of receptor for activated C kinase 1 and protein kinase C-alpha and beta isoforms in brains of morphine-treated rats. Br J Pharmacol 1999, 127:343-348

221. Wan L, Su L, Xie Y, Liu Y, Wang Y, Wang Z: Protein receptor for activated C kinase 1 is involved in morphine reward in mice. Neuroscience 2009, 161:734-742.

222. Liu Q, Wang X, Liu Y, Lu R, Yuan Q, Yang B, Zhou J, Wang Y, Wang Z: RACK1 inhibits morphine re-exposure via inhibition of Src. Neurol Res 2011, 33:56-62

223. Liu QF, Wang X, Yuan Q, Liu YY, Lu R, Wang YH, Jiang Z, Wang ZR: RACK1, a potential target to decrease morphine reward in mice. Arch Ital Biol 2009, 147:131-140

224. Vagts AJ, He DY, Yaka R, Ron D: Cellular adaptation to chronic ethanol results in altered compartmentalization and function of the scaffolding protein RACK1. Alcohol Clin Exp Res 2003, 27:1599-1605.

225. Jeanblanc J, He DY, McGough NN, Logrip ML, Phamluong K, Janak PH, Ron D: The dopamine D3 receptor is part of a homeostatic pathway regulating ethanol consumption. J Neurosci 2006, 26:1457-1464.

226. Logrip ML, Janak PH, Ron D: Dynorphin is a downstream effector of striatal BDNF regulation of ethanol intake. FASEB J 2008, 22:2393-2404.

227. Wang J, Lanfranco MF, Gibb SL, Yowell QV, Carnicella S, Ron D: Longlasting adaptations of the NR2B-containing NMDA receptors in the dorsomedial striatum play a crucial role in alcohol consumption and relapse. J Neurosci 2010, 30:10187-10198.

228. Zylinska L, Guerini D, Gromadzinska E, Lachowicz L: Protein kinases A and C phosphorylate purified Ca2+-ATPase from rat cortex, cerebellum and hippocampus. Biochim Biophys Acta 1998, 1448:99-108.

doi:10.1186/1478-811X-9-22

Cite this article as: Adams et al:: RACK1, A multifaceted scaffolding protein: Structure and function. Cell Communication and Signaling 2011 9:22. 